\title{
Monitoring and characterisation of sand-mud sedimentation processes
}

\author{
Alan J. S. Cuthbertson ${ }^{1}$. Olugbenga Ibikunle ${ }^{1}$. \\ W. John McCarter ${ }^{1}$ • Gerard Starrs ${ }^{1}$
}

Received: 12 November 2015 / Accepted: 2 May 2016 / Published online: 25 May 2016

(C) The Author(s) 2016. This article is published with open access at Springerlink.com

\begin{abstract}
Estuaries and tidal inlets are often characterised by the presence of both cohesive and non-cohesive sediments. Knowledge of the sedimentation behaviour of sand-mud mixtures is therefore crucial to the understanding and prediction of the time-dependent structure (i.e. mixed or segregated), composition and erodibility of sediment bed deposits developing within these environments. In the current study, a series of settling column tests are conducted to investigate the hindered settling and initial bed consolidation phases of a range of sandclay mixtures to determine the parametric conditions under which bed segregation occurs. A new, non-invasive, electrical resistivity measurement technique is employed to capture both temporal and spatial changes in the density, porosity and composition of the evolving sand-clay bed deposits, complimented by time-lapsed images of the sedimentation process within the column. The results show that the formation of segregated (sand-clay) bed layers with bed deposits is largely controlled by the initial fractional composition (i.e. relative sand and clay concentrations). Specifically, mixtures with low clay contents are shown to form well-defined (sandclay) layer segregation within the resulting deposits, while higher clay contents result in more transitional segregation patterns or no layer segregation (for very high clay
\end{abstract}

Responsible Editor: Michael Fettweis

This article is part of the Topical Collection on the 13th International Conference on Cohesive Sediment Transport in Leuven, Belgium 7-11 September 2015

Alan J. S. Cuthbertson

a.cuthbertson@hw.ac.uk

1 School of Energy, Geoscience, Infrastructure and Society, Heriot-Watt University, Edinburgh EH14 4AS, UK concentrations). The physical mechanisms under which these different segregation types can be generated are illustrated through predictions from an existing polydisperse hindered settling model. This model indicates that the degree of bed segregation, and time scale over which this occurs, correlates well with the difference in predicted hindered settling characteristics and upward displacements associated with the sand and clay fractions, respectively. In this regard, the new experimental dataset provides validation for the polydisperse model (for the first time), with the combined data and model predictions providing new insight into mixed (sand-clay) sedimentation processes.

Keywords Sedimentation $\cdot$ Hindered settling $\cdot$ Bed segregation · Sand-clay mixtures · Electrical resistivity · Settling column

\section{Introduction}

Accurate prediction of the transport and fate of cohesive (e.g. muds, silts) and non-cohesive (e.g. sand) sediments within estuaries and coastal regions relies on physical understanding of the complex interplay between transportation processes such as flocculation, settling, deposition, erosion and consolidation (e.g. Grasso et al. 2015). In this respect, net sedimentation [i.e. an increase in bed level due to the difference in erosion and deposition rates, Winterwerp and van Kesteren (2004)] is most likely to occur within mixed sediment environments such as estuaries and tidal inlets under low energy conditions (i.e. in sheltered near-shore regions and/or at slack water) (te Slaa et al. 2013). By contrast, net erosion and resuspension of bed sediments comprising both cohesive and noncohesive fractions can occur under higher energy conditions through combined tidal and wave actions (Van Ledden 2003; 
Winterwerp and van Kesteren 2004). Accurate measurements of sedimentation and/or erosion rates within estuaries and near-shore coastal regions are therefore crucial to assess the long-term morphodynamic evolution, as well as associated changes to sediment bed composition and structure (e.g. segregation) (e.g. Torfs et al. 1996). In this context, sedimentation poses significant economic, environmental and societal impacts on these sensitive aquatic environments through, for example, siltation of navigation channels, harbours and ports, increased coastal flood risk, loss of intertidal habitat and ecosystems and reduction in water quality (e.g. through increased turbidity and the potential for resuspension of contaminated bed sediments) (Cuthbertson et al. 2008). Furthermore, the adoption for sustainable sediment management strategies to mitigate some of these risks (e.g. dredging and dredge spoil disposal operations) can also induce mixed sediment suspensions and further sedimentation processes.

\subsection{Previous work on sand-mud sedimentation}

The development of mixed or segregated sediment beds within estuaries or tidal basins [i.e. spatial variations in the distribution of sands and muds (van Ledden 2003)] results from the differential sediment behaviour of the cohesive and noncohesive fractions within these mixed sediment environments. In particular, the presence of sand is known to have a strong influence on the mud flocculation (e.g. Manning et al. 2010, 2011; Cuthbertson et al. 2010), hindered settling (e.g. Winterwerp 2002; Cuthbertson et al. 2008; Van and Pham Van Bang 2013) and consolidation (e.g. Toorman and Berlamont 1993; Torfs et al. 1996; Grasso et al. 2014) processes that can lead to the formation of segregated, layered structures within the resulting bed deposits. These mixed sediment processes, and their role in defining the nature of the developing bed structure, are therefore also crucial for determining its subsequent resistance to erosion (e.g. Torfs et al. 1996; te Slaa et al. 2013).

The formation of a sand-mud bed deposit clearly begins with the hindered settling of the different sediment cohesive and non-cohesive fractions from suspension. Previous studies of concentrated monodisperse suspensions of either mud flocs (e.g. Winterwerp 2002) or sand particles (e.g. Cheng 1997) indicated that these hindered settling characteristics arise predominantly from return flow generation and wake formation effects, as well as from increased mixture viscosity and buoyancy effects (see also Winterwerp and van Kesteren 2004). Predictions of these hindered settling characteristics for coastal sediment transport modelling have most often been calculated from the exact form of Richardson and Zaki (1954) formulae or some related variation. However, for suspensions containing both mud flocs and sand particles, a multi-fraction or polydisperse approach is required to fully account for the relative influence of each individual fraction on the settling characteristics of other fractions present in the mixture. In this context, Cuthbertson et al. (2008) developed a two-fraction analytical model, based on the polydisperse formulations of Batchelor (1982) and Davis and Gecol (1994), to predict the hindered settling of both sand particle and mud floc fractions under a wide range of mixture compositions and concentrations. Importantly, when compared to equivalent monodisperse hindered settling models for mud flocs and sand particles within concentrated sand-mud mixtures [based on Winterwerp (2002) and Cheng (1997) formulations, respectively], the new polydisperse approach defined (for the first time) mixture conditions under which the mud flocs would be displaced upwards due to return flow effects generated by the hindered sand fraction settling. Although this polydisperse model was not verified against laboratory data, this differential settling phenomenon appeared to be a prime mechanism for layer segregation within resulting sand-mud bed deposits. Van and Pham Van Bang (2013) developed and applied a similar polydisperse model to investigate segregation (and trapping) effects that occur between mud flocs and sand grains during the hindered settling phase. The authors acknowledged, however, that limitations in the extent of calibration data available (i.e. one $20 \%$ sand $-80 \%$ kaolin test mixture) meant the model needed further validation over a wider range of sandclay mixtures. Grasso et al. (2014) analysed data from a number of previous settling column studies (e.g. Bartholomeeusen et al. 2002; Merckelbach and Kranenburg 2004a; te Slaa et al. 2013; van and Pham Van Bang 2013) investigating hindered settling of sand-mud mixtures over a wide range of initial concentrations and sand contents. The analysis revealed that sand segregation within the resulting deposits was not always observed and appeared to be prevented at a threshold level of the initial relative mud concentration (e.g. Waeles et al. 2008).

Hindered settling characteristics within sand-mud suspensions are therefore thought to largely determine the vertical structure within the resulting bed deposits (e.g. the formation of mixed or segregated deposit layers). Subsequent to this initial bed formation process, however, time-dependent consolidation is driven by the expulsion of pore water from cohesive bed layers, resulting in a strength evolution in the mud bed against erosion (i.e. through an increase in critical shear stress) (e.g. Been and Sills 1981; Merckelbach 2000). Several modelling techniques (of varying complexities) have been proposed to simulate these bed consolidation processes. The most comprehensive and widely used approach, at least for primary consolidation (Grasso et al. 2015), is known as the Gibson model (Gibson et al. 1967), which computes the time evolution of vertical concentration profiles over the unified hindered settling and initial consolidation phases of bed evolution (Toorman 1996). The Gibson theory was developed for, and has been applied successfully to simulate, consolidation processes in monodisperse cohesive sediments (i.e. pure muds). However, it has been noted as being rarely applied to 
mixed sediments (Grasso et al. 2015) and, indeed, Van and Pham Van Bang (2013) described the method as being irrelevant for mixed sediments (e.g. sandy-mud, muddy-sand). Other consolidation models for sand-mud mixtures have been proposed (e.g. Toorman 1996, 1999; Merckelbach and Kranenburg 2004b; Le Hir et al. 2011) but with varying success in the accurate simulation of consolidation for sediment mixtures with medium to high sand contents (i.e. $>10-20 \%$ ) (Grasso et al. 2015). However, the consolidation model proposed by Le Hir et al. (2011) was shown to provide good predictive capabilities for mud consolidation, as well as the capacity to simulate sand-mud segregation within the bed. Grasso et al. (2015) used this model as a basis on which to study numerically mixed sedimentation and consolidation processes and particularly those initial conditions leading to segregation. This model was noted as achieving excellent predictive capabilities in simulating both sediment height evolution and vertical concentration profiles but required model parameters to be calibrated for each run.

\subsection{Previous work on sand-mud characterisation techniques}

The availability and reliability of non-intrusive measurement techniques for monitoring the development of mixed (sandmud) sediment beds (i.e. structure and composition) remain a major challenge for improving understanding of sedimentation processes in mixed sedimentary environments (Ha et al. 2010). The majority of sedimentation and consolidation studies are conducted in settling columns (te Slaa et al. 2013), focussing on vertical profile measurements of bulk density development within the consolidating bed, as well as excess pore water pressure dissipation. Previous settling column investigations have used a range of non-intrusive measurement methods for bulk density and bed porosity including X-ray and $\gamma$-ray techniques (e.g. Been and Sills 1981; Merckelbach 2000; Villaret et al. 2010) and a prototype magnetic resonance imaging (MRI) system (e.g. Pham Van Bang et al. 2008). The advantage of X-ray and $\gamma$-ray techniques is the measurement of continuous density profiles to a high resolution $\left( \pm 2 \mathrm{~kg} \mathrm{~m}^{-3}\right)$ (te Slaa et al. 2013). However, they have distinct disadvantages in terms of the health and safety risks associated with potential exposure to radiation hazards. Furthermore, when investigating the consolidation of sandmud mixtures, all these non-intrusive techniques (i.e. MRI, $\mathrm{X}$-ray and $\gamma$-ray) are limited to the measurement of bulk density or porosity profiles (i.e. through the total volumetric solids concentration $\phi_{\mathrm{s}}$ of the sand-mud mixture). Hence, no additional information on the individual volumetric concentrations of mud or sand fractions can be determined (Van and Pham Van Bang 2013).

One of the main aims of the current study is, therefore, to demonstrate the potential of a new non-intrusive bed characterisation technique, based on electrical resistivity measurements of bulk density and porosity. A key advantage of this technique is that it allows virtually continuous, noninvasive profiling of the developing bed deposit structure from sedimentation of sand-clay mixtures over a wide range of initial concentrations and mixture compositions, without any risk from radiation hazards. Furthermore, temporal and spatial changes in fractional (sand-mud) bed layer composition within the resulting deposits can be identified through calibration against known resistivity values for specific sand-mud mixtures. It is noted that a similar measurement technique, based electrical conductivity to measure density, was utilised in the study by te Slaa et al. (2013) for characterising silt-rich sedimentation processes. However, the technique developed and employed herein has the distinct advantage in that by utilising a 4-point measurement technique (rather than 2-point), the effects of electrode polarisation are removed, resulting in reliable bulk measurements (see Section 2.2.2).

The second key aim of the current study is to provide a significant dataset on sand-clay sedimentation processes, over a wide range of initial mixture concentrations and compositions to (i) investigate further the parametric dependence of mixed and segregated bed deposit formation and (ii) test the polydisperse hindered settling formulation proposed by Cuthbertson et al. (2008) in terms of its predictive capabilities for the generation of these mixed and segregated bed deposits (see discussion in Section 4.1). The electrical resistivity measurements presented in the paper are complemented by timelapsed photography of the developing deposits, which allowed both qualitative aspects of the bed formation to be observed and discussed, as well as quantitative measurements of hindered settling and initial bed consolidation rates through the evolution of the upper bed interface alone.

\section{Methodology}

\subsection{Experimental setup}

Figure 1a shows a schematic representation of the $500-\mathrm{mm}$ high acrylic-walled, rectangular sedimentation column (internal plan dimensions $150 \mathrm{~mm} \times 150 \mathrm{~mm}$ ) used in the experimental study. The demountable top and bottom end plates of the column formed an effective seal against leakage and evaporation during the sedimentation runs and allowed the column and electrode arrangement to be cleaned following each run.

Electrical resistance measurements were made continuously throughout each sedimentation run using a 4-point electrode measurement technique. Within this arrangement (Fig. 1b), the current $I$ is passed between two outer electrodes [i.e. $A$ and $B$, Fig. 1b] and the potential $V$ is measured between two inner electrodes [i.e. $M$ and $N$, Fig. 1b]. Within the sedimentation column, the electrical measurements were made 
Fig. 1 a Schematic representation of sedimentation column setup, detailing pin-electrode arrangement, and b four-electrode resistivity array showing current (solid) and equipotential (dashed) lines

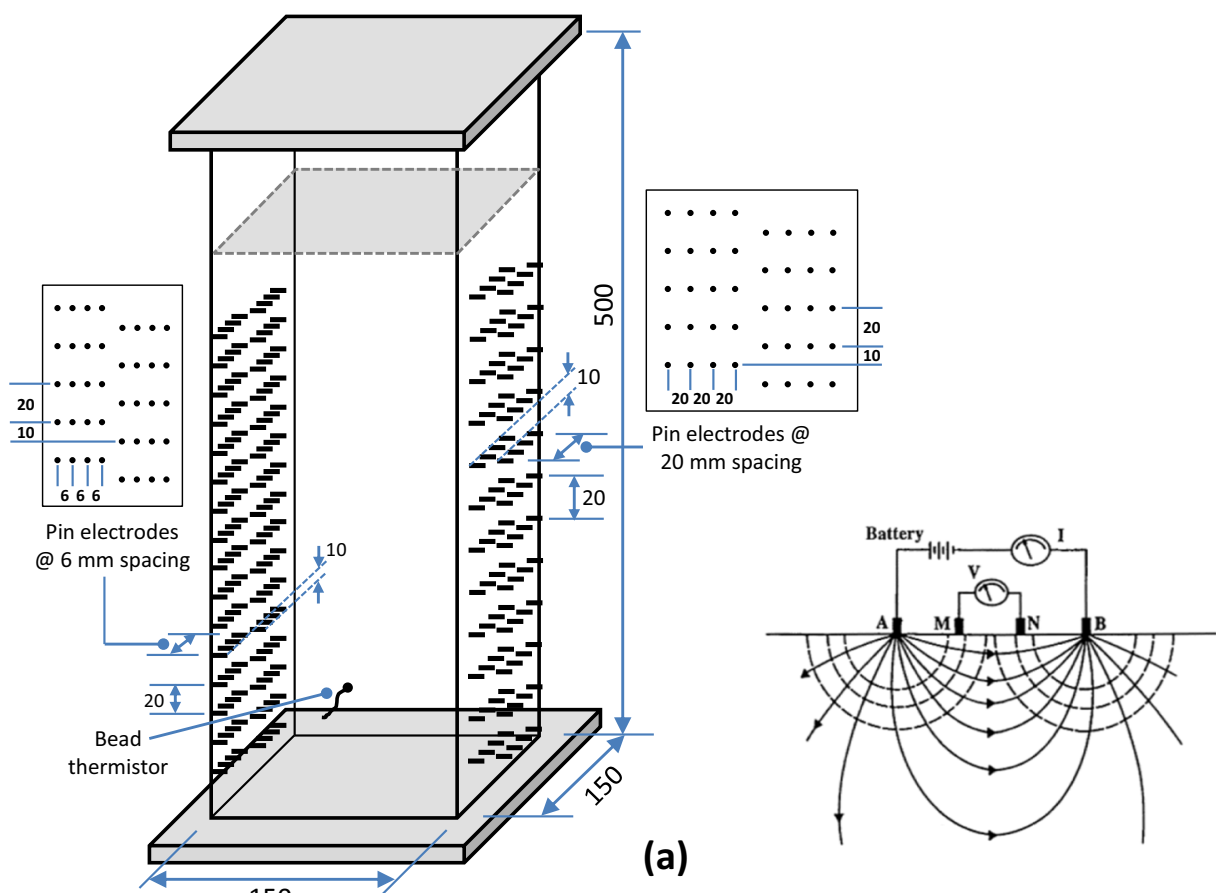

(b) using a vertical array of $35 \times 4$-electrode sets embedded in two opposite walls of the column (Fig. 1a) with their tips flush with the inner wall surfaces to ensure that the electrodes did not interfere directly with the sedimentation process. Each individual four-electrode set comprised four 1.6-mm-diameter stainless steel pins set in a horizontal row at a spacing of 6 and $20 \mathrm{~mm}$, respectively, on the opposite column walls, and a vertical spacing of $10 \mathrm{~mm}$ between individual offset fourelectrode sets in both configurations (see Fig. 1a). This varying spatial (i.e. horizontal) electrode resolution allowed its influence on measurement sensitivity to be ascertained, while the offset arrangement of the individual electrode sets was mainly for fabrication purposes. In general, initial testing of the two-electrode configurations indicated that the electric fields produced by the 6-mm-spaced electrodes provided much higher spatial resolution around sharp transitions in bed deposit properties (i.e. segregated bed layers), while penetrating sufficiently into the column to ensure results were not dominated by wall effects. Small perturbations in the resistance measurements were also observed between different electrode sets when testing the column using standard $0.5 \mathrm{M}$ $\mathrm{NaCl}$ solution (i.e. of known resistivity). These perturbations were easily resolved via appropriate adjustments to the electrode geometric factors for each 4-point electrode pair (see Section 2.2.2).

Each set of 4-point electrodes was connected to a mainframe and AC resistance bridge [Stanford Research Systems (SRS) SIM900 and SIM925], via a series of four-pole relay switching multiplexers (SRS SIM925). This system facilitated automated electrical resistance measurements (with frequency of the applied field set at $1 \mathrm{kHz}$ ) at each individual electrode set, with a measurement sequence from the bottom to top sets providing vertical profiles of the electrical resistance properties for the evolving sedimentation process at 35-s intervals (i.e. individual resistance measurements were obtained by the multiplexing system at 1-s intervals).

Sand-clay sediment mixtures were generated within the column using kaolin clay [Polwhite B kaolinite $\left(\mathrm{SiO}_{2}=47 \%\right.$; $\mathrm{Al}_{2} \mathrm{O}_{3}=37 \%$ ); $d=\sim 0.5-20 \mu \mathrm{m} ; d_{50}=2 \mu \mathrm{m}$; plastic (PL) and liquid (LL) limits $=28$ and $54 \%$, respectively; $\mathrm{SG}=2.59]$ and fine sand [CLS33-Superfine high silica sand $\left(\mathrm{SiO}_{2}>95 \%\right)$; $\left.d=\sim 75-500 \mu \mathrm{m} ; d_{50}=150 \mu \mathrm{m} ; \mathrm{SG}=2.64\right)$. The range of sand-clay mixture compositions tested is presented in Table 1, together with the experimental parameters for individual sedimentation runs. Individual sand-clay mixtures were prepared with brine solutions of different salinities (i.e. 0-40 ppt; $\gamma_{\mathrm{f}}=997.8-1028.1 \mathrm{~kg} \mathrm{~m}^{-3}$ ) to form dense suspensions with initial solid mass concentrations varying between $C_{\mathrm{s}}=330$ and $813 \mathrm{~kg} \mathrm{~m}^{-3}$ (Table 1). Each mixture was transferred into the column in a single-shot and agitated by a grid stirrer before being left to settle. The resulting hindered settling and depositional characteristics for the sand-clay mixtures were investigated over the full duration of individual runs (i.e. up to 24 and $72 \mathrm{~h}$ for ST and LT runs, respectively; see Table 1) with time series datasets on the evolving bed deposit properties (e.g. bulk density, porosity and composition) measured using the automated electrical resistance profiling technique. In addition, time-lapsed images using a Canon EOS 600D digital camera (18 MP) were collected to measure both hindered settling and initial bed consolidation rates (i.e. through tracking the 


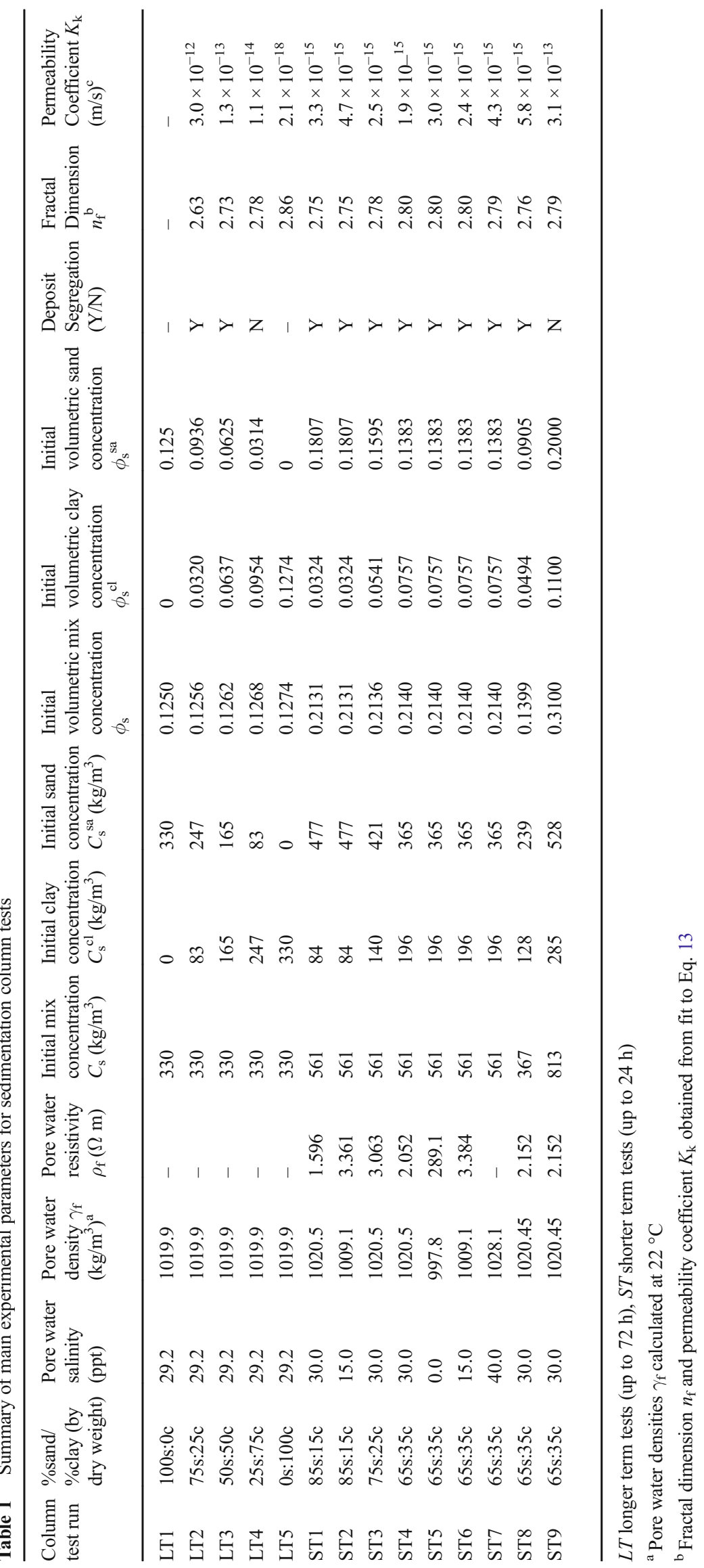


evolution of the bed interface), as well as to obtain (mainly) qualitative observations on the resulting bed deposit structure (i.e. mixed or segregated).

\subsection{Electrical resistance measurements}

\subsubsection{Background theory}

The basis on which the use of electrical resistance measurements is proposed to characterise the formation and evolution of mixed sediment deposits arises from the fact that natural sediment grains are typically poor conductors of electricity. Hence, the conduction of electrical current propagation within a saturated sediment sample will occur primarily through the water-filled pore space. The bulk resistivity $\rho_{\text {bulk }}(\Omega \mathrm{m})$, which is a material property of the saturated sediment, will therefore depend on (i) the conductivity of the pore fluid and (ii) the micro-structure of the sediment bed (i.e. sand-clay composition and mineralogy, porosity, pore geometry, tortuosity and connectivity). Within the current study, which considers the sedimentation of idealised mixtures of high-silica sand and kaolinite clay, the mineralogy of these sediments is welldefined (see Section 2.1) and, as such, is of secondary importance compared to the fractional (sand-clay) mixture composition, pore characteristics and conductivity of pore fluid.

Conventional treatment of resistivity data in saturated rocks has been to utilise the formation factor $F$ (e.g. Archie 1942; Winsauer et al. 1952; Atkins and Smith 1961), which is defined as the ratio of bulk resistivity $\rho_{\text {bulk }}$ of the saturated rock to the resistivity of the saturating fluid $\rho_{\mathrm{f}}$ (i.e. pore water) (see Table 1). This formation factor $F$ is then related to the rock porosity $\varphi$ through the relationship,

$F=\frac{\rho_{\text {bulk }}}{\rho_{\mathrm{f}}}=a \varphi^{-m}$

where the exponent $m$ is the cementation exponent and is related to the tortuosity and connectivity of the pore network within the rock and $a$ is a correction factor, which is valid over a particular range of porosities $\varphi$. A wide range of values have been reported for $m$ and $a$ for different rock and sediment formations, with $a$, typically in the range $0.4-2.5$ and $m=1.2-2.5$ (e.g. Worthington 1993; Khalil and Santos 2011). Values of $m$ and $a$ are characteristic for a given porous rock formation and are determined empirically. This model, comprising a non-conductive solid phase and a conducting interstitial aqueous phase, has been successfully extended to study the sedimentation characteristics of clay suspensions (Blewett et al. 2001), where $\rho_{\text {bulk }}$ is the resistivity of the settling clay-water mixture and $\rho_{\mathrm{f}}$ is the resistivity of the pore water.
Provided appropriate calibration has been conducted, Eq. 1 can be used to determine more physically relevant properties of a porous material, such as solid volume concentration $\phi_{\mathrm{s}}$ (i.e. ratio of the volume of solids to the total wet volume) of the sediment particles, viz,

$\phi_{\mathrm{s}}=(1-\varphi)=\left[1-\left(\frac{a}{F}\right)^{\frac{1}{m}}\right]$

For a pure clay-water (or sand-water) mixture, the corresponding mass concentration $C_{\mathrm{s}}$ and bulk density $\gamma_{\text {bulk }}$ are clearly given by the expressions

$C_{\mathrm{s}}=\phi_{\mathrm{s}} \gamma_{\mathrm{s}}$

$\gamma_{\text {bulk }}=\left(\phi_{\mathrm{s}} \gamma_{\mathrm{s}}+\varphi \gamma_{\mathrm{f}}\right)$

where $\gamma_{\mathrm{s}}$ and $\gamma_{\mathrm{f}}$ are the densities of the clay (or sand) particles and the pore fluid, respectively. For a sand-clay-water mixture, the solid volume concentration $\phi_{\mathrm{s}}=\phi_{\mathrm{s}}^{\mathrm{sa}}+\phi_{\mathrm{s}}^{\mathrm{cl}}$, where $\phi_{\mathrm{s}}^{\mathrm{sa}}$ and $\phi_{\mathrm{s}}{ }^{\mathrm{cl}}$ are the volumetric concentrations of the sand and clay fractions, respectively. Hence, the mass concentration $C_{\mathrm{s}}$ and bulk densities of the sand-clay-water mixture are given by the modified expressions,

$C_{\mathrm{s}}=\phi_{\mathrm{s}}^{\mathrm{sa}} \gamma_{\mathrm{s}}^{\mathrm{sa}}+\phi_{\mathrm{s}}^{\mathrm{cl}} \gamma_{\mathrm{s}}^{\mathrm{cl}}$

$\gamma_{\text {bulk }}=\left(\phi_{\mathrm{s}}^{\mathrm{sa}} \gamma_{\mathrm{s}}^{\mathrm{sa}}+\phi_{\mathrm{s}}^{\mathrm{cl}} \gamma_{\mathrm{s}}^{\mathrm{cl}}+\varphi \gamma_{\mathrm{f}}\right)$

where $\gamma_{\mathrm{s}}^{\mathrm{sa}}$ and $\gamma_{\mathrm{s}}^{\mathrm{cl}}$ are the densities of the sand and clay particles, respectively. If, however, $\gamma_{\mathrm{s}}^{\mathrm{sa}} \approx \gamma_{\mathrm{s}}^{\mathrm{cl}}\left(=\gamma_{\mathrm{s}}\right)$, then Eq. 6 can be recast, as follows

$$
\begin{aligned}
\gamma_{\text {bulk }} & =\gamma_{\mathrm{s}}\left(\phi_{\mathrm{s}}^{\mathrm{sa}}+\phi_{\mathrm{s}}^{\mathrm{cl}}\right)+\varphi \gamma_{\mathrm{f}}=\gamma_{\mathrm{s}}(1-\varphi)+\varphi \gamma_{\mathrm{f}} \\
& =\gamma_{\mathrm{s}}-\varphi\left(\gamma_{\mathrm{s}}-\gamma_{\mathrm{f}}\right)
\end{aligned}
$$

Dividing through by the pore fluid density $\gamma_{\mathrm{f}}$ allows the normalised bulk density $\gamma_{\text {bulk }} / \gamma_{\mathrm{f}}$ to be determined from Eqs. 2 and 7 , such that

$\frac{\gamma_{\text {bulk }}}{\gamma_{\mathrm{f}}}=\frac{\gamma_{\mathrm{s}}}{\gamma_{\mathrm{f}}}-\left(\frac{a}{F}\right)^{\frac{1}{m}}\left(\frac{\gamma_{\mathrm{s}}-\gamma_{\mathrm{f}}}{\gamma_{\mathrm{f}}}\right)$

However, the general validity of Eq. 8 requires that the Archie equation (Eq. 1), for the formation factor $F$ as a function of porosity, be universally valid over a wide range of sand-clay-water mixture conditions. Specifically, from Eq. 1 , it is clear that empirical parameters $a$ and $m$ cannot be fitted to satisfy the condition: $F \rightarrow 1$ as $\varphi \rightarrow 1$ (i.e. very dilute suspensions, where $\gamma_{\text {bulk }} \rightarrow \gamma_{\mathrm{f}}$ ), unless $a$ is set as unity. However, as noted above, the value of $a$ can vary within wide limits. As a consequence, the relationship between normalised bulk density $\gamma_{\text {bulk }} / \gamma_{\mathrm{f}}$ and formation factor $F$ is determined through a best-fit power law to calibration measurements on predefined sand-clay-water mixtures (discussed below). 


\subsubsection{Four-point versus 2-point electrode measurements}

One of the key advantages to adopting a 4-point electrode measurement system (Fig. 1b), as opposed to a more standard 2-point system (e.g. te Slaa et al. 2013), is the elimination of electrode polarisation effects, which can significantly affect the electrical resistance measurements obtained (i.e. through electrode drift) within a sample of the sediment bed deposit. Additionally, as the acrylic column walls can be regarded as a non-conducting boundary, the four-electrode method has the added advantage that the measured resistance $R$ within the sediment deposit can be converted directly to the bulk resistivity $\rho_{\text {bulk }}$ through consideration of the electrode geometry, i.e.

$\rho_{\text {bulk }}=2 \pi r R$

where $r$ is the centre-to-centre electrode spacing (i.e. 6 and $20 \mathrm{~mm}$ ). The 4-point arrangement therefore allows a bulk property of the sediment deposit (i.e. $\rho_{\text {bulk }}$ ) to be determined relatively easily without the need for additional geometric calibration, as required for the equivalent 2-point electrode configurations.

\subsubsection{Temperature effects}

For ionically conducting saturated sediments, such as the sand-clay-water mixtures under investigation, the bulk resistivity $\rho_{\text {bulk }}$ and temperature are also known to be linked through an Arrhenius-type relationship (Blewett et al. 2003; Hayley et al. 2007):

$\rho_{\text {bulk }}=\operatorname{Ae}^{\left[\frac{E_{\mathrm{a}}}{\Re T}\right]}$

where $T$ is the absolute temperature $(\mathrm{K}), A$ is the preexponential constant $(\Omega \mathrm{cm}), \Re$ is the universal gas constant $(=8.314 \mathrm{~kJ} / \mathrm{mol} / \mathrm{K})$ and $E_{\mathrm{a}}$ is the activation energy for the conduction process $(\mathrm{kJ} / \mathrm{mol})$. Although the experimental runs for this study were undertaken in a temperature-controlled laboratory (i.e. $21 \pm 2{ }^{\circ} \mathrm{C}$ ), it was considered appropriate to account for the potential effects from minor fluctuations in ambient temperature on the measured resistance $R$ values within the sedimentation column (and, hence, the bulk resistivity values $\rho_{\text {bulk }}$ ). Temperature variations within the settling sand-clay mixtures were monitored using bead thermistors embedded in the column walls. This allowed all resistivity values to be corrected to an equivalent resistivity $\rho_{\text {ref }}$ at a predefined reference temperature $T_{\text {ref }}$ of $25^{\circ} \mathrm{C}$ (i.e. $298.15 \mathrm{~K}$ ):

$\rho_{\text {ref }}=\rho_{\text {bulk }} e^{\frac{E_{a}}{\Re^{2}}\left[\frac{1}{T_{\text {ref }}}-\frac{1}{T}\right]}$

where $E_{\mathrm{a}}=17.8 \mathrm{~kJ} / \mathrm{mol}$ was used throughout in this correction (Blewett et al. 2003).

\subsubsection{Surface conduction effects}

In saturated sand-clay mixtures, the clay particles develop a diffuse, electrical double layer that can give rise to surface conduction processes and, thus, represent a possible additional parallel current conduction path through the mixed sediment sample. However, this effect will only be significant in low porosity systems (i.e. highly compacted, saturated clay formations with well-aligned clay particles) and when the interstitial water phase has a high resistivity (e.g. Wildenschild et al. 2000; Glover 2010; Ponziani et al. 2012; Revil et al. 2013). The contribution of surface conduction to the measured resistance becomes increasingly less significant: (i) when the pore water resistivity decreases (e.g. through increasing salinity) and/or (ii) if the saturated deposit is not fully compacted through the consolidation processes (e.g. freshly deposited sediment beds). In such circumstances, ionic conduction via the interstitial aqueous phase will dominate over any contribution from surface conduction. In the current study, surface conduction from bed compaction effects is unlikely to have any significant contribution to the resistivity measurements made during the test runs as experiments focused on the hindered settling and initial consolidation phases only. Additionally, for the majority of experimental runs conducted (see Table 1), the resistivity of the pore mixing water $\rho_{\mathrm{f}}$ (i.e. brine solutions) was sufficiently low to ensure that any surface conduction had a negligible effect on the bulk resistance measurements (Glover 2010; Ponziani et al. 2012).

\section{Experimental results}

\subsection{Qualitative observations on sand-clay segregation}

Within the settling column arrangement employed in the current study, the typical sedimentation and bed formation processes displayed by different sand-clay mixtures are essentially one-dimensional, with the downward movement of sediments and the upward displacement of pore fluid (Torfs et al. 1996). With differential settling effects between the sand and clay fractions in the mixtures, it would be expected that larger, denser sand particles should settle faster than smaller, less-dense clay flocs, leading to a segregated bed deposit [i.e. with a clay-rich deposit layer overlying a sand-dominated bottom bed layer (e.g. Williamson 1991; Torfs, et al. 1996; te Slaa et al. 2013)]. However, the influence of small-scale interactions between sand particles and clay flocs during this hindered settling phase, together with the upward displaced pore water, suggests that the resulting deposit structure (and the parametric conditions controlling it) may be more complex. In this regard, differential settling effects are likely to be controlled by the total solid volumetric concentration $\phi_{\mathrm{s}}$, as well as the relative volumetric concentrations of sand $\phi_{\mathrm{s}}{ }^{\mathrm{sa}}$ and clay 
$\phi_{\mathrm{s}}{ }^{\mathrm{cl}}$ fractions, in the initial sediment mixture (Cuthbertson et al. 2008). The parametric influence of $\phi_{\mathrm{s}}, \phi_{\mathrm{s}}^{\mathrm{sa}}$, and $\phi_{\mathrm{s}}{ }^{\mathrm{cl}}$ on the resulting sand-clay deposits will be discussed in detail later.

Time-lapsed images of the sand-clay sedimentation process within the settling column were used to describe (i) the developing bed layer structure and, in particular, segregation between the depositing sand and clay fractions and (ii) the displacement of the interface formed between the developing bed deposit layer and supernatant pore water (discussed in Section 3.2). Figure 2 shows example time-lapsed images of the formation of bed deposits for two sand-clay mixtures tested. In Fig. 2a, the 85s:15c mixture (run ST1, Table 1) begins to segregate almost immediately on initiation of the run [i.e. elapsed time $t=10 \mathrm{~s}$, Fig. 2a], with a sand-dominated deposit layer forming at the base of the column [i.e. $t=10 \mathrm{~s} \rightarrow 2 \mathrm{~min}$, Fig. 2a]. Above this base layer, a sharp interface forms with the overlying clay-dominated bed layer that develops over a significantly longer time [i.e. $t \rightarrow 6 \mathrm{~h}$, Fig. 2a], as indicated by the temporal displacement of the upper bed interface with the supernatant pore water. Figure $2 b$ presents similar images of the sedimentation process for the $65 \mathrm{~s}: 35 \mathrm{c}$ mixture (run ST5, Table 1). Here, the formation of a sand-dominated base layer is shown to occur over a longer time period [i.e. $t \rightarrow 60 \mathrm{~min}$, Fig. 2b], with a less well-defined interface at the transition to the overlying clay-dominated layer. Furthermore, it is apparent from this run that a proportion of the clay fraction is trapped in the sand-dominated base layer, while some sand particles become trapped as clusters in the upper claydominated layer during the bed formation process.
In both these 85 and $65 \%$ sand runs, it is noted that the total mass $C_{\mathrm{s}}$ and volumetric $\phi_{\mathrm{s}}$ concentrations for the sand-clay mixtures were equivalent (i.e. $C_{\mathrm{s}}=561 \mathrm{~kg} \mathrm{~m}^{-3} ; \phi_{\mathrm{s}}=0.213-$ 0.214 , Table 1 ), while the corresponding fractional volumetric sand-mud concentrations, $\phi_{\mathrm{s}}^{\mathrm{sa}}$ and $\phi^{\mathrm{cl}}$, varied between the mixtures (i.e. $\phi_{\mathrm{s}}^{\mathrm{sa}}=0.1807$ and 0.1383 and $\phi_{\mathrm{s}}{ }^{\mathrm{cl}}=0.0324$ and 0.0757 , respectively, Table 1). While it is noted that some degree of bed deposit segregation was observed for the majority of sand-clay mixtures tested (see Table 1), the above finding suggests that the most highly segregated bed conditions tend to occur for sand-clay mixtures with higher $\phi_{\mathrm{s}}{ }^{\mathrm{sa}}$ and lower $\phi_{\mathrm{s}}^{\mathrm{cl}}$ values, respectively. However, it is also interesting to note that the two mixtures for which no segregation was observed in the deposit had the highest volumetric concentrations of clay [i.e. $\phi_{\mathrm{s}}{ }^{\mathrm{cl}}=0.095$ (LT4) and $\phi_{\mathrm{s}}{ }^{\mathrm{cl}}=0.110$ (ST9), Table 1], irrespective of the corresponding volumetric sand content [i.e. $\phi_{\mathrm{s}}{ }^{\mathrm{sa}}=0.0314$ (LT4) and $\phi_{\mathrm{s}}{ }^{\mathrm{sa}}=0.20$ (ST9), Table 1]. This latter finding suggests that a critical value of $\phi_{\mathrm{s}}{ }^{\mathrm{cl}}$ exists where sand particles in the mixture are prevented from settling and forming a segregated bottom layer within the column, analogous to a gelling concentration (i.e. Winterwerp and van Kesteren 2004) at which point the clay (flocs) will form a space-filling network.

Figure 3 presents similar time-lapsed images of the developing bed deposit to investigate closer the structure and composition of the segregated sand and clay layers that occur within these deposits over longer time periods. In this regard, Fig. 3i(a-f) show images of the partially segregated deposit arising from the 50s:50c mixture tested in run LT3 (Table 1). Figure 3i(a) again highlights the rapid sand-dominated layer
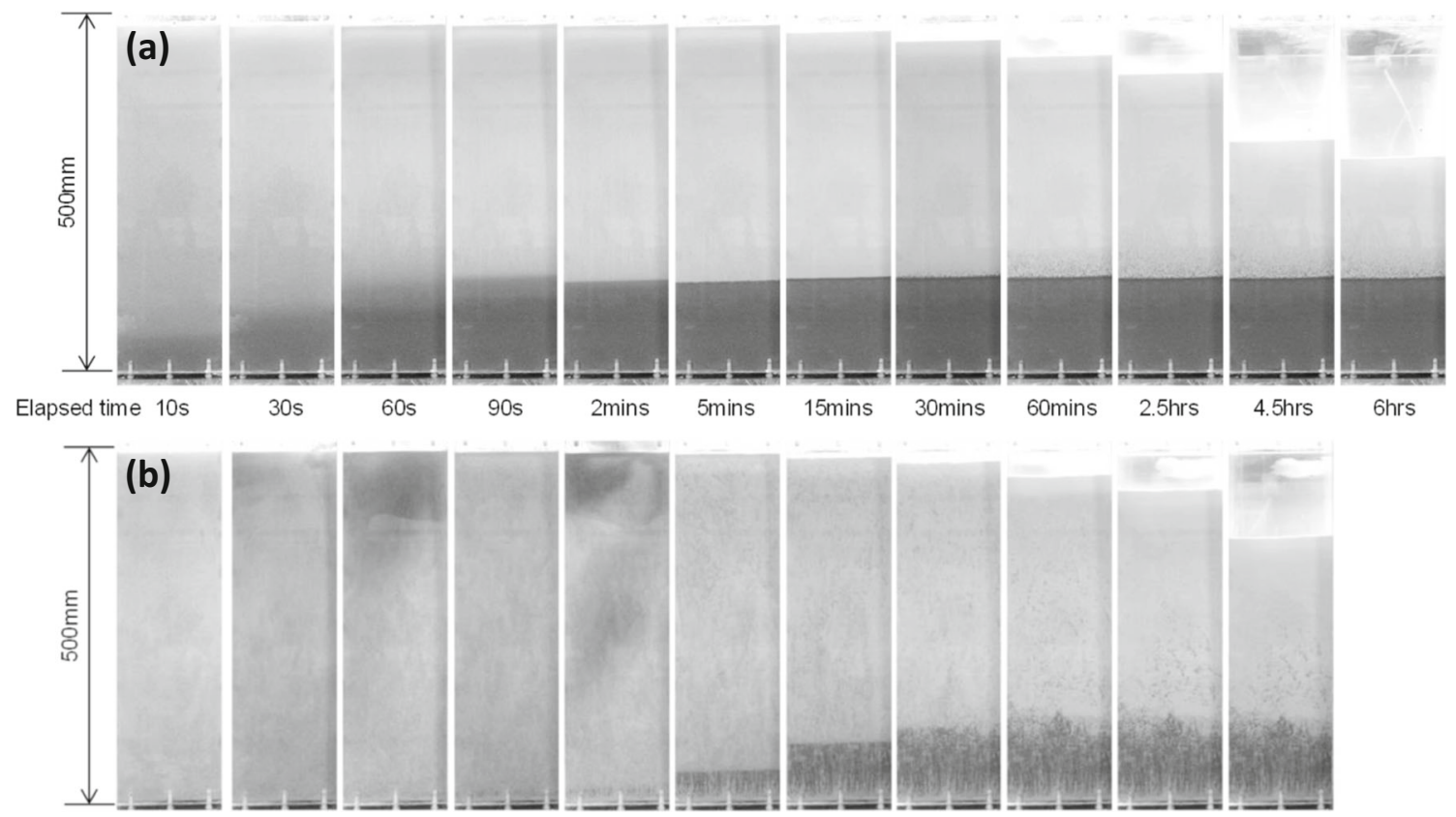

Fig. 2 Time-lapsed images of sand-clay sedimentation process at elapsed times $t$ shown for a run ST1 (i.e. 85s:15c mixture) and b run ST5 (i.e. $65 \mathrm{~s}: 35 \mathrm{c}$ mixture) (see Table 1) 
(i)
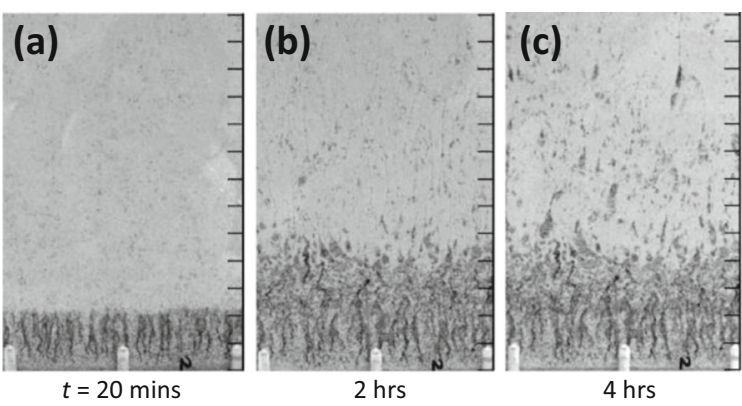
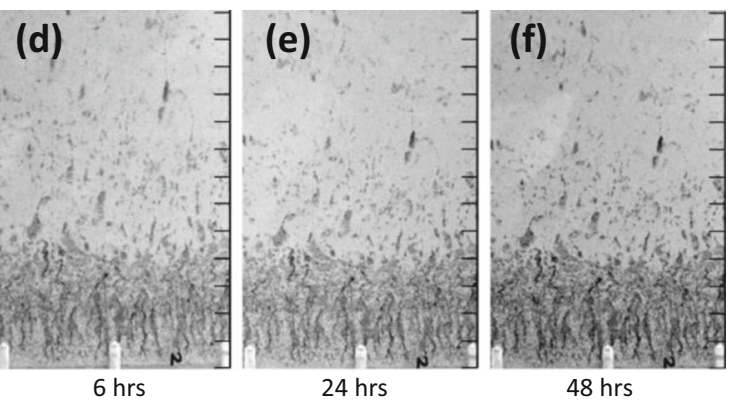

(ii)

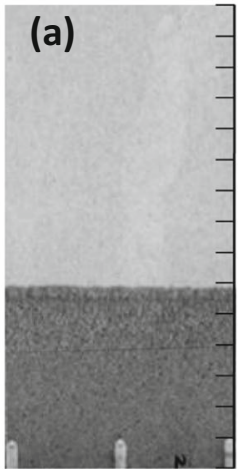

$t=10$ mins

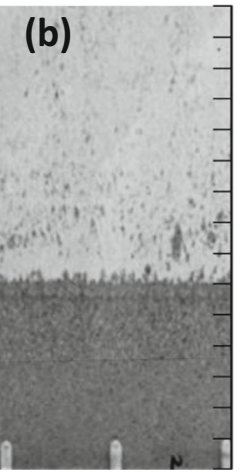

$3 \mathrm{hrs}$

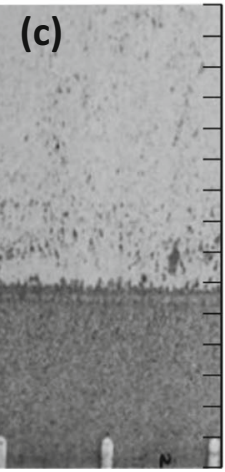

$6 \mathrm{hrs}$

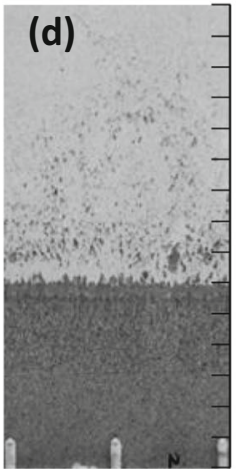

$24 \mathrm{hrs}$

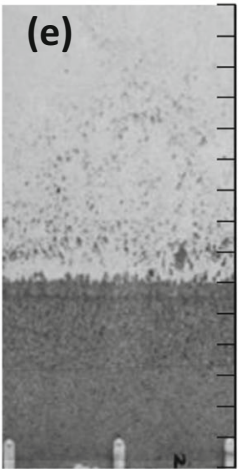

$48 \mathrm{hrs}$

Fig. 3 Time-lapsed images showing segregated deposit formation at elapsed times $t$ shown for (i) run LT3 (i.e. 50s:50c) and (ii) run LT2 (i.e. 75s:25c) (see Table 1). Vertical scale divisions $=10 \mathrm{~mm}$

formation at the column base (i.e. $z$ up to $\sim 21-\mathrm{mm}$ thick at $t=20 \mathrm{~min}$ ), with near-vertical banding indicative of the development of clay-pore water "dewatering" channels during this initial settlement phase. This base layer appears to be overlain by a patchier, sand-dominated layer interspersed with trapped clay [i.e. $z=20 \sim 45 \mathrm{~mm}$ after $t=2 \mathrm{~h}$, Fig. 3i(b)]. Above this, a thicker clay-dominated layer containing discrete sand patches is then deposited [i.e. $z=45 \sim 110 \mathrm{~mm}$ after $t=4$ h, Fig. 3i(c)]. This layer is shown to compact over the time, as indicated by the downward displacement of the trapped sand patches (i.e. for $t=240 \rightarrow 2880 \mathrm{~min}$, Figs. 3i(c-f)]. The presence of these discrete sand patches within a clay-dominated layer is particularly interesting as it suggests a proportion of the sand fraction becomes trapped at a significant elapsed time (i.e. $t>2 \mathrm{~h}$ ), most probably, as the volumetric concentration of the clay fraction $\phi_{\mathrm{s}}{ }^{\mathrm{cl}}$ in this layer reaches a gelling concentration (see later discussion). Above this, the remainder of the clay suspension deposits to form a (relatively) sand-free surface layer within the bed deposit [i.e. $z>\sim 90 \mathrm{~mm}$, Fig. 3i(f)].

In comparison, Fig. $3 i$ shows the temporal development of the strongly segregated bed deposit for the $75 \mathrm{~s}: 25 \mathrm{c}$ mixture (run LT2, Table 1). As with the 85s:15c mixture (Fig. 2a), this dominant fraction deposits rapidly to form a thick sand layer [i.e. $z=0 \sim 58 \mathrm{~mm}$ at $t=10 \mathrm{~min}$, Fig. 3ii(a)] at the column base. This is overlain subsequently by a clay-dominated layer, with trapped sand patches, above the well-defined sand-clay interface [i.e. after $180 \mathrm{~min}$, Fig. 3ii(b)]. This upper layer is again shown to compact over time [i.e. $t=180 \rightarrow 2880 \mathrm{~min}$, Fig. 3ii(b-e)] but is less obvious than observed in run LT3 [i.e. Fig. 3i(c-f)] due to (i) the lower volumetric clay concentration in run LT2, compared to LT3 (i.e. $\phi_{\mathrm{s}}{ }^{\mathrm{cl}}=0.032$ and 0.064 , respectively), and/or (ii) the formation of a sharp segregational interface between the incompressible base sand layer and overlying clay-rich deposit.

\subsection{Hindered settling and consolidation rates}

The time-lapsed images also provided a quantitative record of sedimentation rates for different sand-clay mixtures from the vertical displacement of the upper bed interface between the settling clay layer and the supernatant pore water (see Fig. 2). In this context, Fig. 4a displays the temporal change in the upper interface elevation for the range of sand-clay mixtures tested in ST1-ST9 runs (Table 1). It is clear from this plot that an inflection point exists (on the log-log scale) on the temporal evolution of these interfacial profiles that delineates the transition between hindered settling behaviour and so-called phase I consolidation (Merckelbach and Kranenburg 2004b). It is interesting to note from Fig. 4a that the vertical interfacial displacement during the hindered settling phase is reduced, and occurs over a longer duration, for sand-clay mixtures with relatively high volumetric clay concentrations $\phi_{\mathrm{s}}{ }^{\mathrm{cl}}$ and/or 

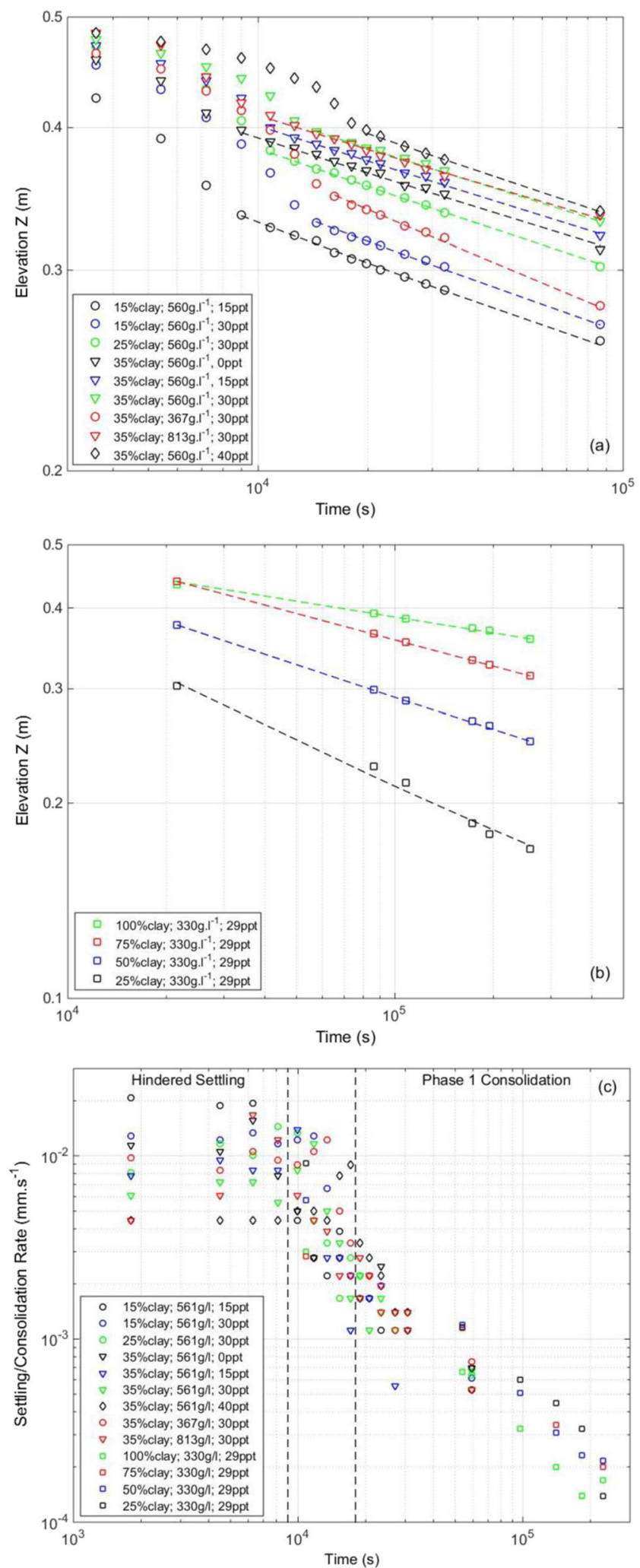

Fig. 4 Temporal variation in upper clay layer interface with the supernatant pore water for a ST runs and b LT runs (Table 1). c Corresponding temporal variation in hindered settling and phase I consolidation rates $\left(\mathrm{mm} \mathrm{s}^{-1}\right)$ for all runs where the salinity of the pore water is increased. These findings are as expected when considering the form of the hindered settling velocity formula proposed by Winterwerp (2002) for a mono-dispersed suspension of cohesive sediment flocs:

$w_{\mathrm{s}}^{\mathrm{cl}}=\frac{\left(1-\phi_{\mathrm{floc}}^{\mathrm{cl}}\right)\left(1-\phi_{\mathrm{s}}^{\mathrm{cl}}\right)}{1+2.5 \phi_{\mathrm{floc}}^{\mathrm{cl}}} w_{\mathrm{s}, 0}^{\mathrm{cl}}$

where $\phi_{\text {floc }}^{\text {cl }}$ is the volumetric concentration of clay flocs within the suspension and $w_{\mathrm{s}, 0}^{\mathrm{cl}}$ is the fall velocity of a single clay floc. Thus, (i) higher clay concentrations $\phi_{\mathrm{s}}{ }^{\mathrm{cl}}$ will have a larger hindering effect on sedimentation rates due to increased buoyancy [i.e. accounted for by the hindered settling factor $\left(1-\phi_{\mathrm{S}}{ }^{\mathrm{cl}}\right)$, Eq. 12], while (ii) higher salinities may speculatively result in larger clay flocs (and, hence, larger volumetric clay floc concentration $\phi_{\text {floc }}^{\mathrm{cl}}$ ), at least over a range of salinity values, with a resulting increase in return flow and viscosity effects [i.e. accounted for by the hindered settling factors $\left(1-\phi_{\text {floc }}^{\mathrm{cl}}\right)$ and $\left(1+2.5 \phi_{\text {floc }}^{\mathrm{cl}}\right)$, respectively, Eq. 12]. A more detailed discussion of the parametric influences of sand-clay concentrations and pore water salinities on the initial settling characteristics of the mixtures is presented in Section 4.1.

After this initial hindered settling phase, the subsequent temporal evolution of the clay-water interface in Fig. 4a [and Fig. $4 \mathrm{~b}$ for interfacial data from LT2 to LT5 runs] represents the onset of phase I consolidation (Merckelbach and Kranenburg 2004b). Merckelbach (2000) proposed a model to investigate this initial consolidation stage, based on observations of the evolving interface elevation $h(t)$ alone, such that:

$h(t)=\left(\frac{2-n}{1-n} \zeta_{\mathrm{cl}}\right)^{\frac{1-n}{2-n}}\left((n-2) K_{\mathrm{k}} \frac{\gamma_{\mathrm{s}}-\gamma_{\mathrm{f}}}{\gamma_{\mathrm{f}}}\right)^{\frac{1}{2-n}} t^{\frac{1}{2-n}}$

where $\zeta_{\mathrm{cl}}$ is the Gibson height $\left[\zeta_{\mathrm{cl}}=h \cdot \phi_{\mathrm{s}}{ }^{\mathrm{cl}} /\left(1-\phi_{\mathrm{s}}{ }^{\mathrm{sa}}\right)\right.$, where volumetric concentrations $\phi_{\mathrm{s}}{ }^{\mathrm{cl}}$ and $\phi_{\mathrm{s}}{ }^{\mathrm{sa}}$ are assumed initially to be uniformly distributed in the column of height $h$ ]. The permeability parameter $K_{\mathrm{k}}$ and fractal dimension $n_{\mathrm{f}}$ [i.e. through $n=2 /\left(3-n_{\mathrm{f}}\right)$ ] are determined by fitting Eq. 13 to the temporal evolution of the measured clay-water interface [when plotted on double log scales, Fig. 4a, b]. These model predictions are shown by the dashed lines in Fig. 4a, b, with the corresponding fitted values of $K_{\mathrm{k}}$ and $n_{\mathrm{f}}$ shown in Table 1 . In general, the predicted fractal dimensions $n_{\mathrm{f}}$ for the clay-rich upper layer (i.e. $n_{\mathrm{f}}=2.63-2.86$ for LT runs; $n_{\mathrm{f}}=2.75-2.80$ for ST runs, Table 1) are broadly as expected within the evolving bed layer (e.g. Winterwerp and van Kesteren 2004) and much larger than typical values $\left(n_{\mathrm{f}} \approx 1.7-2.2\right)$ found for settling flocs in the water column. These $n_{\mathrm{f}}$ values, describing the structure formation of the upper clay-dominated bed layer, tend to increase slightly as $\phi_{\mathrm{s}}{ }^{\text {cl }}$ values within the mixture increase, as observed in Van and Pham Van Bang (2013), te Slaa et al. 
(2013) and Grasso et al. (2015). Predicted values of the permeability coefficient $K_{\mathrm{k}}\left(=2.1 \times 10^{-18}-3.1 \times 10^{-13}\right.$, Table 1$)$ are also in broad agreement with representative values obtained from previous studies (e.g. Merckelbach 2000; Winterwerp and van Kesteren 2004).

Figure $4 \mathrm{c}$ shows an ensemble plot of the hindered settling and phase I consolidation rates $\left(\mathrm{mm} \mathrm{s}^{-1}\right)$ for all LT and ST runs, indicating clearly the transition region between these two modes of behaviour between elapsed run times $t=9000 \rightarrow 18,000 \mathrm{~s}$, depending on the sand-clay mixture tested. Hindered settling rates are also shown to vary in the order $O\left(10^{-3}-10^{-2}\right) \mathrm{mm} \mathrm{s}^{-1}$, depending on mixture composition (and particularly $\phi_{\mathrm{s}}{ }^{\mathrm{cl}}$ values), while consolidation rates decrease from $O\left(10^{-3}\right) \mathrm{mm} \mathrm{s}^{-1}$ to $O\left(10^{-4}\right) \mathrm{mm} \mathrm{s}^{-1}$ with increasing elapsed time, as expected. These results indicate that higher clay concentrations $\phi_{\mathrm{s}}{ }^{\mathrm{cl}}$ within the initial sand-clay mixture inhibit both the initial hindered settling phase and subsequent formation of the mixed bed deposit, broadly in agreement with the findings of Torfs et al. (1996).

\subsection{Electrical resistivity profiles}

Within the settling column tests, the temporal changes in the formation factor $F$ profiles during both the hindered settling and bed formation phases of the sand-clay sedimentation process were measured using the 4-point electrode arrays (at 6mm electrode spacing) mounted in the column walls. The bulk resistivity, $\rho_{\text {bulk, }}$, was evaluated at different elevations in the column via Eq. 9, while the pore water resistivity $\rho_{\mathrm{f}}$ was evaluated from the supernatant brine solution that formed above the sand-clay mixture during sedimentation. (Note that it is reasonable to assume that the supernatant water has the same resistivity as the interstitial pore water between the particles within the sand-clay deposit). Figure 5 presents colour maps of the temporal change in formation factor $F$ profiles over the first hour of the sedimentation process for four different sandclay-water mixtures. For the $85 \mathrm{~s}: 15 \mathrm{c}$ mixture (salinity $=30$ ppt) (i.e. run ST1, Table 1), Fig. 5a shows the rapid development $(t=0 \rightarrow \sim 150 \mathrm{~s})$ of a strongly segregated bed with high formation factors $(F=3.5-4.2)$ at the column base $(Z=0-125 \mathrm{~mm})$ and lower formation factors $(F=1-1.5)$ above. The well-defined interface that develops between the rapidly forming base sand deposit layer and overlying claydominated layer is consistent, in elevation, with the sharp transition between higher and lower formation factors. Figure $5 \mathrm{~b}$ presents a similar colour map plot of $F$ profiles for the $75 \mathrm{~s}: 25 \mathrm{c}$ mixture (salinity $=30 \mathrm{ppt}$ ) (i.e. run ST3, Table 1 ) but with a reduction in formation factor values $(F=3.2-3.8)$ observed in the base layer, which is reduced in thickness $(Z=0-110 \mathrm{~mm})$ and also develops over a longer time period $(t=0 \rightarrow \sim 350 \mathrm{~s})$ compared to the $85 \mathrm{~s}: 15 \mathrm{c}$ mixture. This reflects the influence of increased clay concentration, $\phi_{\mathrm{s}}{ }^{\mathrm{cl}}$, both on the hindered settling characteristics of sand fraction and the increased presence of trapped clay in the sand-dominated layer at the column base (indicated by lighter vertical streaks or "dewatering" channels, Fig. 5b). In Fig. 5c the formation factor colour map for the $65 \mathrm{~s}: 35 \mathrm{~s}$ mixture (salinity $=30 \mathrm{ppt}$ ) (run ST4, Table 1) indicates that a thinner sand-dominated layer $(z=0-85 \mathrm{~mm})$ with lower $F$ values $(F=2.4-3.6)$ develops over a significantly longer time period $(t=0 \rightarrow \sim 1300 \mathrm{~s})$. This has a more indistinct interface with the clay-dominated upper bed layer, which is reflected in the more gradual transition in formation factor $F$ values between these two layers. Finally, Fig. 5d shows the corresponding colour map of $F$ profiles for the same $65 \mathrm{~s}: 35 \mathrm{c}$ mixture but with a different pore fluid salinity (0 ppt) (run ST5, Table 1). It is apparent from the colour map that the key bed layer development characteristics for this mixture (i.e. layer thicknesses and development time; range of $F$ values) are very similar to the previous $65 \mathrm{~s}: 35 \mathrm{c}$ (30 ppt) mixture (Fig. 5c). In summary, the formation factor colour maps highlight key differences in the nature and extent of segregation that occurs in the bed deposits of different sandclay-water suspensions. These are associated particularly with (i) the sharpness of the interfacial transition between the sanddominated base layer and overlying clay-dominated layer and (ii) the quantity of clay trapped in the sand-dominated base layer and vice versa. It is interesting to note, however, that the pore water salinity appears to have little influence on the key characteristics of this initial bed layer formation phase.

\subsubsection{Calibration measurements}

In order to relate measured formation factor, $F$, profiles to physically relevant characteristics and properties of the sandclay-water deposits, a series of calibration measurements were conducted on sand-clay samples of known composition and derived physical properties (e.g. porosity $\varphi$, volumetric concentration $\phi_{\mathrm{s}}$, bulk density $\gamma_{\text {bulk }}$ ). These calibration tests were conducted in a specially designed ring cell with 4-point electrodes embedded in the cell walls in both horizontal and vertical arrays (see Fig. 6a). Saturated mixtures of sand and kaolin clay of known fractional composition (i.e. $\phi_{\mathrm{s}}^{\mathrm{sa}}$ and $\phi_{\mathrm{s}}{ }^{\mathrm{cl}}$ ) were prepared with $0.5 \mathrm{M} \mathrm{NaCl}$ solution (salinity $30 \mathrm{ppt}$ ) to an appropriate consistency such that sand-clay segregation could not occur within the test samples. Each mixture was placed carefully, in turn, within the test ring cell (Fig. 6a) with the embedded pin electrodes used to obtain 4-point resistivity measurements. The specific gravity $G_{\mathrm{s}}$ of the mixture constituents (i.e. sand, kaolin clay and brine solution) was determined, with the bulk density $\gamma_{\text {bulk, }}$, porosity $\varphi$ and void ratio $e$ determined for each sample in accordance with standard practice (i.e. BS 1377: part 2: 1990) (see Table 2). A total of three samples were tested for each sand-clay mixture composition. Figure $6 \mathrm{~b}$ shows the variation in formation factor $F$ $\left(=\rho_{\text {bulk }} / \rho_{\mathrm{f}}\right)$ plotted versus the calculated sample porosity $\varphi$ for the range of sand-clay mixtures tested. The best-fit power 

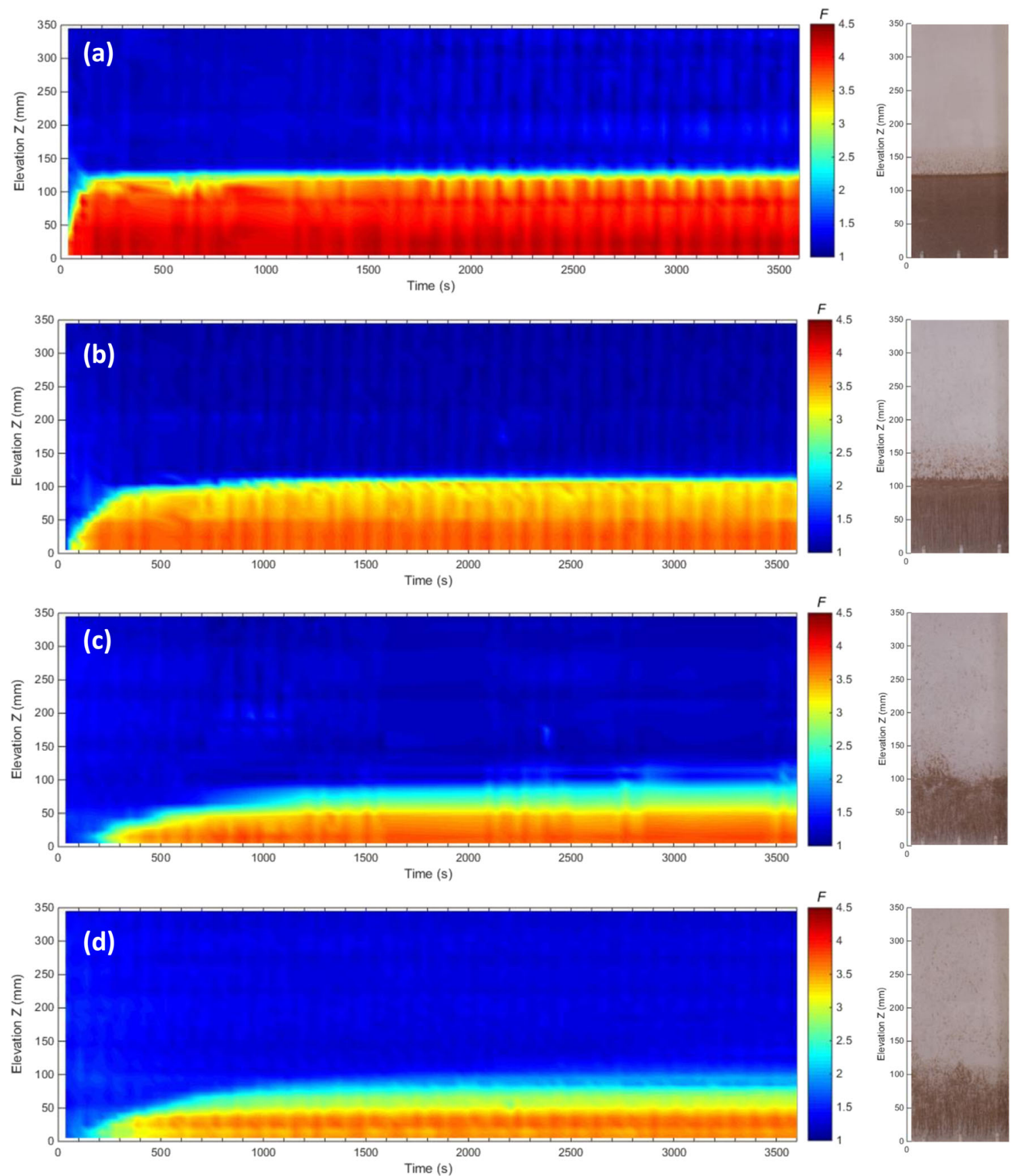

Fig. 5 Time series colour map plots of the variation in measured formation factor $F$ profiles during the first hour of sand-clay mixture settlement for runs a ST1 (85s:15c), b ST3 (75s:25c), c ST4 (65s:35c) and d ST5 (65s:35c) (see Table 1). Corresponding images show bed deposit layer formation at $t=1 \mathrm{~h}$

relationship through this calibration data is shown to have the same form as the Archie (1942) relationship (Eq. 1), such that:

$F=\frac{\rho_{\text {bulk }}}{\rho_{\mathrm{f}}}=1.584 \phi^{-1.128}$

Hence, coefficients $a$ and $m$ in Eq. 1 are evaluated as 1.584 and 1.128 , respectively, and are in general agreement with values obtained from other studies in unconsolidated, saturated soil $[a=0.62-1.97$ (e.g. Boyce 1968) and $m=1.0-1.2$ (e.g. McCarter et al. 2005)]. It is reemphasised here that the range of applicability of Eq. 14 (and, hence, Eq. 1 in general) is limited by the condition: $F \rightarrow 1$ as $\varphi \rightarrow 1$ (i.e. pore fluid only). Hence, Eq. 14 can only be considered valid over the range of porosities $(\varphi=0.35-0.7)$ for the calibration mixtures tested. As indicated previously, this limiting condition also has implications for general validity of Eq. 8, which relates normalised bulk density $\gamma_{\text {bulk }} / \gamma_{\mathrm{f}}$ with formation factor $F$. Indeed, this relationship is shown in Fig. 6c (dashed trend line) 
Fig. 6 a Test ring cell used for sand-clay calibration measurements. b Derived Archie (1942) relationship between formation factor $F$ and porosity $\varphi$. c Derived relationships between normalised bulk density $\gamma_{\text {bulk }} / \gamma_{\mathrm{f}}$ and formation factor $F$. d

Relationship between $\gamma_{\text {bulk }} / \gamma_{\mathrm{f}}$ and sand content (\%) within sand-clay test sample
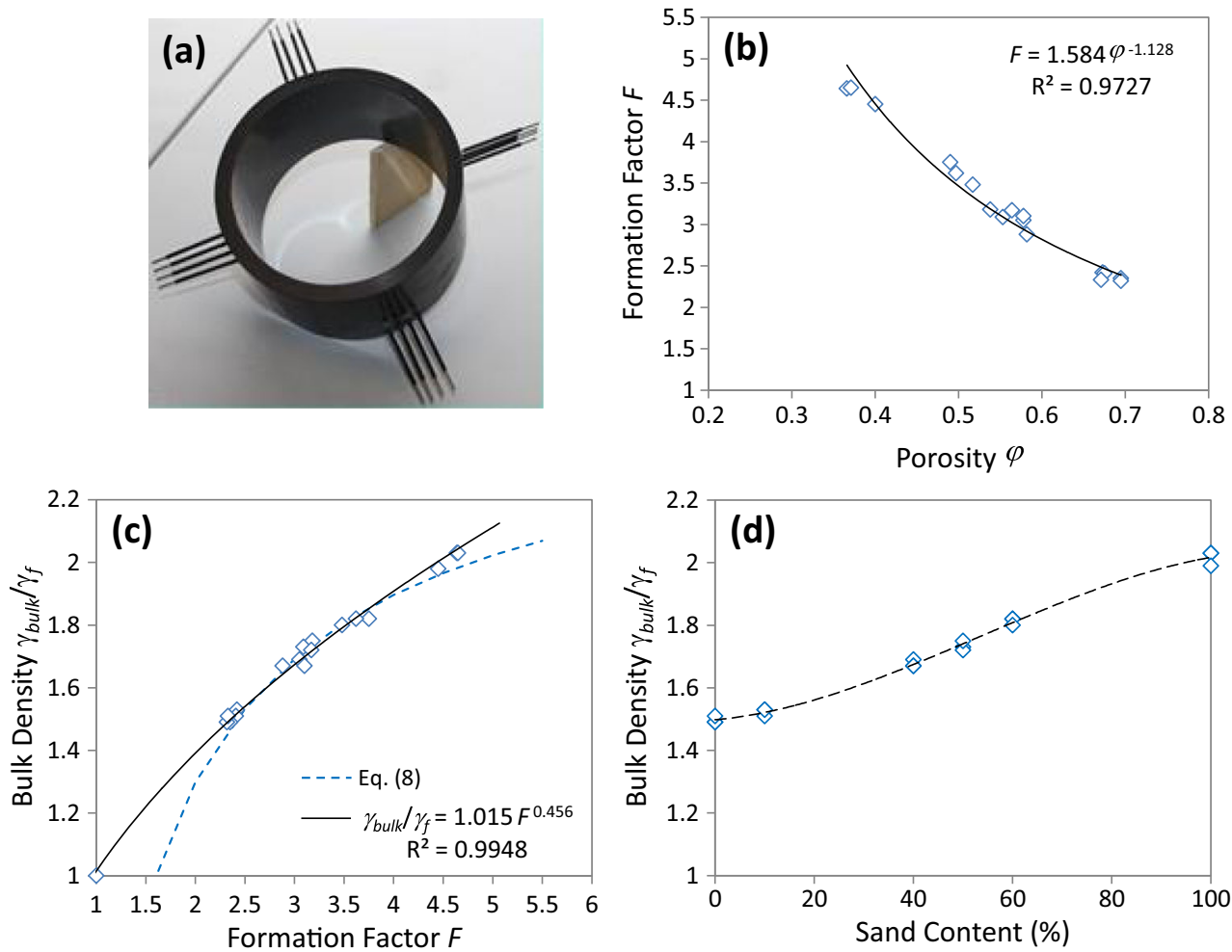

and, while reasonable fit is demonstrated within the calibration data range, the required condition that $\gamma_{\text {bulk }} / \gamma_{\mathrm{f}} \rightarrow 1$ as $F \rightarrow 1$ is clearly not satisfied. Hence, an improved fit to the calibration data [i.e. solid line, Fig. 6c] is proposed $\left(R^{2}=0.9948\right)$ that also better satisfies the imposed condition is proposed:

$\frac{\gamma_{\text {bulk }}}{\gamma_{\mathrm{f}}}=1.015 F^{0.456}$

This equation can therefore be used to predict evolving normalised density $\left(\gamma_{\text {bulk }} / \gamma_{\mathrm{f}}\right)$ profiles within the sand-clay deposits directly from electrical resistivity measurements. Furthermore, Fig. 6d indicates how the normalised bulk density of the prepared sand-clay calibration samples increases non-linearly (i.e. $\gamma_{\text {bulk }} / \gamma_{\mathrm{f}}=\sim 1.5 \rightarrow \sim 2.0$ ) with sand content (i.e. $0 \rightarrow 100 \%$ ). It should be noted that the calibration plots in Fig. 6 have been derived from tests on unconsolidated, saturated sand-clay mixtures and, hence, are more representative of freshly deposited bed conditions. As such, the electrical properties of sand-clay suspensions (i.e. prior to bed layer formation) or heavily consolidated sand-clay bed layers would be expected to vary from the range of formation factors $(F=2.32-4.65)$ measured in the calibration tests. However, the physical properties of the former can clearly be estimated from Eq. 15 when extended back to the required condition $\gamma_{\text {bulk }} / \gamma_{\mathrm{f}}=1$ when $F=1$.

\subsubsection{Bulk density profiles}

With the aid of the sand-clay mixture calibrations outlined above, time series colour maps of measured formation factor $F$ profiles (Fig. 5) are transformed into normalised bulk
Table 2 Physical properties of calibration sand-clay sample mixtures

\begin{tabular}{llll}
\hline \%sand/\%clay (by dry weight) & Bulk density ${ }^{\mathrm{a}, \mathrm{b}} \gamma_{\text {bulk }}\left(\mathrm{kg} \mathrm{m}^{-3}\right)$ & Porosity $\varphi^{\mathrm{b}}$ & Void ratio $e^{\mathrm{b}}$ \\
\hline 0s:100c & 1513.0 & 0.686 & 2.185 \\
$10 \mathrm{~s}: 90 \mathrm{c}$ & 1531.9 & 0.675 & 2.077 \\
$40 \mathrm{~s}: 60 \mathrm{c}$ & 1689.4 & 0.579 & 1.375 \\
$50 \mathrm{~s}: 50 \mathrm{c}$ & 1734.6 & 0.552 & 1.232 \\
$60 \mathrm{~s}: 40 \mathrm{c}$ & 1821.4 & 0.501 & 1.004 \\
$100 \mathrm{~s}: 0 \mathrm{c}$ & 2026.0 & 0.379 & 0.610 \\
\hline
\end{tabular}

${ }^{\mathrm{a}} G_{\mathrm{s}}=2.59$ (Polwhite B kaolin clay); $G_{\mathrm{s}}=2.64$ (CLS33 superfine sand)

${ }^{\mathrm{b}}$ Tabulated figures are average values from three calibration samples per mix 
density $\gamma_{\text {bulk }} / \gamma_{\mathrm{f}}$ profiles via Eq. 15 . In addition, expressing term $(a / F)^{1 / m}$ as porosity $\varphi$ in Eq. 8, we can obtain:

$\phi=\frac{\gamma_{\mathrm{s}}-\gamma_{\text {bulk }}}{\gamma_{\mathrm{s}}-\gamma_{\mathrm{f}}}$ where, by definition, $\varphi \rightarrow 1$ when $\gamma_{\text {bulk }} \rightarrow \gamma_{\mathrm{f}}$ (i.e. very dilute suspensions) and $\varphi \rightarrow 0$ as $\gamma_{\text {bulk }} \rightarrow \gamma_{\mathrm{s}}$ (i.e. solid bed with no pore space). Figure 7 shows contour plots of the temporal change in the normalised bulk density $\gamma_{\text {bulk }} / \gamma_{\mathrm{f}}$ profiles over the initial sedimentation period for the four sand-clay mixtures
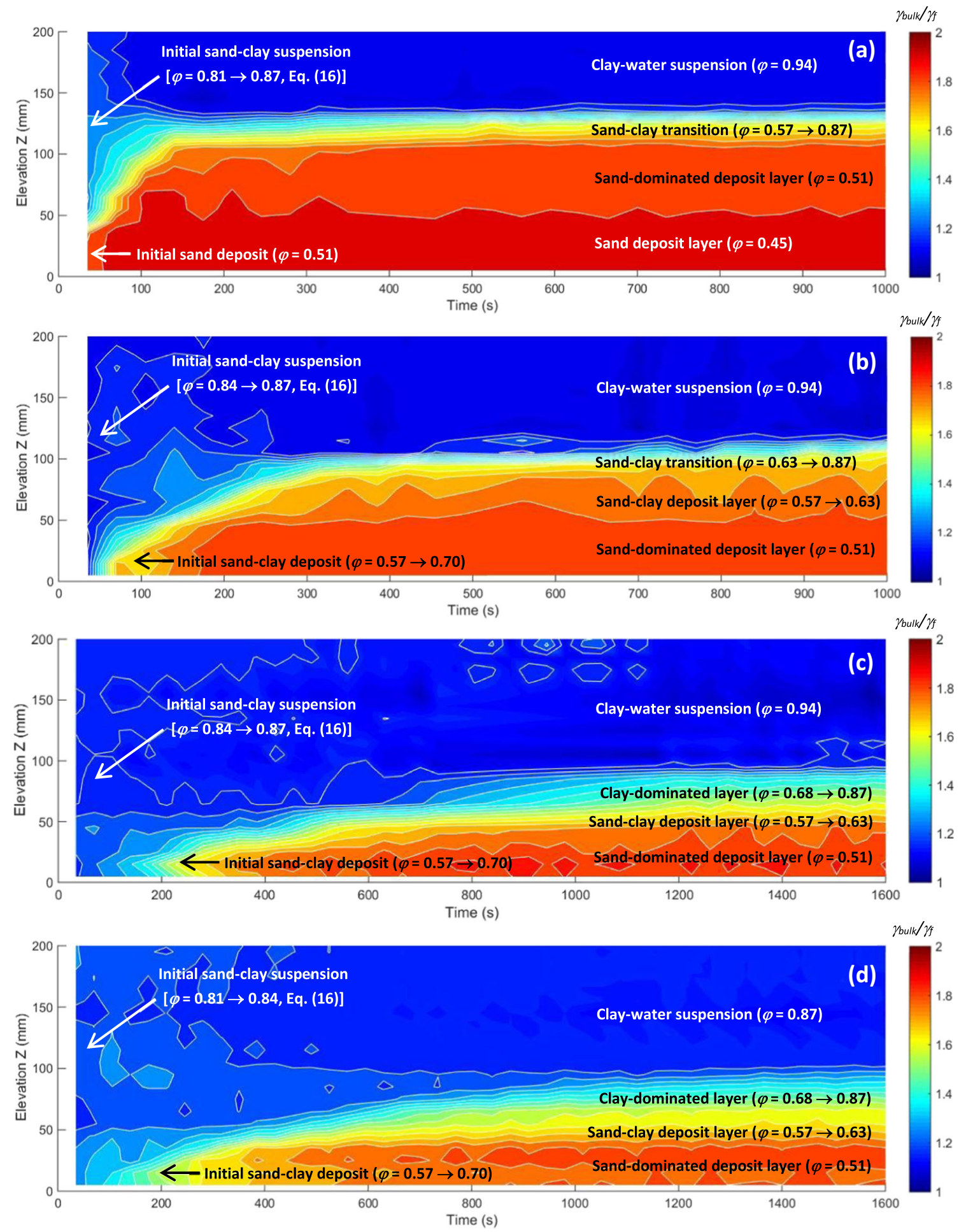

Fig. 7 Initial temporal development of normalised bulk density $\gamma_{\text {bulk }} / \gamma_{\mathrm{f}}$ within sand-clay bed deposit layers for runs a ST1 (85s:15c), b ST3 (75s:25c), c ST4 (65s:35c) and d ST5 (65s:35c) (see Table 1). Values of porosity $\varphi$ shown are indicative (based on Eq. 16) 
(i.e. runs ST1, ST3, ST4 and ST5, Table 1) previously considered in Fig. 5. Within Fig. 7a, the $85 \mathrm{~s}: 15 \mathrm{c}$ (30 ppt) mixture is shown initially (i.e. $t=75 \mathrm{~s})$ to vary from $\gamma_{\text {bulk }} / \gamma_{\mathrm{f}}=1.15$ at $Z=200 \mathrm{~mm}$ to $\gamma_{\text {bulk }} / \gamma_{\mathrm{f}}=1.8$ at $Z=5 \mathrm{~mm}$, representative of the differential (sand-clay) settling and layer segregation that occurs immediately following the start of the test (see Section 3.1). The resulting bed develops quickly to form a stable, bottom, sanddominated layer (i.e. $Z=0 \rightarrow \sim 100 \mathrm{~mm}$ over $t=0 \rightarrow$ $\sim 150 \mathrm{~s})$ with $\gamma_{\text {bulk }} / \gamma_{\mathrm{f}}$ values $>\sim 1.8 \rightarrow \sim 1.9$ [i.e. sand content $>\sim 60 \%$, Fig. $6 \mathrm{~d}$ ]. Indicative values of bed porosity $\varphi$ (Eq. 16) vary from $\varphi=0.45$ in this sand-dominated base layer up to $\varphi=0.94$ in the upper clay-water suspension, with the sand-clay interface region shown to occur between $Z \approx 105 \rightarrow 135 \mathrm{~mm}$. The vertical extent $(\sim 30 \mathrm{~mm})$ of this interface region may be due partly to the electrode resolution (i.e. 6-mm horizontal electrode spacing and 10$\mathrm{mm}$ vertical spacing between each 4-point electrode set; see Section 2.1), which may lead to measurement blurring at sharp interfacial changes (i.e. discontinuities) in deposit composition. Figure $7 \mathrm{~b}$ shows that for the $75 \mathrm{~s}: 25 \mathrm{c}$ (30 ppt) mixture, the initial formation of the sanddominated bottom deposit layer (i.e. $\gamma_{\mathrm{bulk}} / \gamma_{\mathrm{f}}>1.8$, $\varphi=\sim 0.51$ ) occurs over a longer time scale (i.e. $t=0 \rightarrow$ $\sim 350 \mathrm{~s})$. This base layer is overlain by a mixed sandclay deposit layer (i.e. $\gamma_{\text {bulk }} / \gamma_{\mathrm{f}}=\sim 1.6$ to $\sim 1.7 ; \varphi=0.57-$ $0.63)$, with the elevation of the sand-clay transition to the upper clay-water suspension $\left(\gamma_{\text {bulk }} / \gamma_{\mathrm{f}}<\sim 1.15\right.$, $\varphi=0.94$ ) increasing with time (i.e. $Z \approx 105 \rightarrow 120 \mathrm{~mm}$ as $t=350 \rightarrow 1000 \mathrm{~s})$. In Fig. 7c, the developing bed structure for the $65 \mathrm{~s}: 35 \mathrm{c}(30 \mathrm{ppt})$ mixture indicates some differences from that of the $75 \mathrm{~s}: 25 \mathrm{c}(30 \mathrm{ppt})$ mixture (i.e. Fig. 7b), namely: (i) the required time for the bottom sand-dominated layer to develop is, again, significantly lengthened (i.e. $t=0 \rightarrow \sim 1000 \mathrm{~s}$ ), and (ii) there is greater evidence of a transitional change in the resulting bed deposit from the sand-dominated bed layer at the column base (i.e. $\gamma_{\text {bulk }} / \gamma_{\mathrm{f}}=\sim 1.7 \rightarrow \sim 1.8 ; \varphi=0.51$ ) to an upper clay-dominated layer (i.e. $\gamma_{\mathrm{bulk}} / \gamma_{\mathrm{f}}=\sim 1.2 \rightarrow \sim 1.5$; $\varphi=0.68-0.87)$. By contrast, Fig. $7 d$ shows that the initial bed development for the $65 \mathrm{~s}: 35 \mathrm{c}(0 \mathrm{ppt})$ mixture is very similar to that of the $65 \mathrm{~s}: 35 \mathrm{c}(30 \mathrm{ppt})$ mixture (i.e. Fig. 7c), both in terms of the transitional nature of the resulting deposit (sand $\rightarrow$ clay-dominated), as well as in the layer density $\gamma_{\text {bulk }} / \gamma_{\mathrm{f}}$ and porosity $\varphi$ values. In summary, these contour plots of $\gamma_{\text {bulk }} / \gamma_{\mathrm{f}}$ show the initial stages of the bed layer development for different sand-clay mixture compositions and indicate quantitatively how the individual deposit layers form over time, as well as providing an indication of their composition and structure (i.e. through corresponding $\gamma_{\text {bulk }} / \gamma_{\mathrm{f}}$ and porosity $\varphi$ values in the different bed regions). Again, however, the results are indicative of the pore water salinity having minimal influence on the initial bed development $(t=0 \rightarrow 1000-1600 \mathrm{~s})$ or the physical properties (i.e. density, porosity) of the segregated bed layers therein.

Figures 8 and 9 present the longer term development of normalised density $\gamma_{\text {bulk }} / \gamma_{\mathrm{f}}$ profiles over 24 and $48 \mathrm{~h}$, respectively, for a range of sand-clay mixtures. Figure $8 \mathrm{a}$ compares the changes in normalised density profiles for
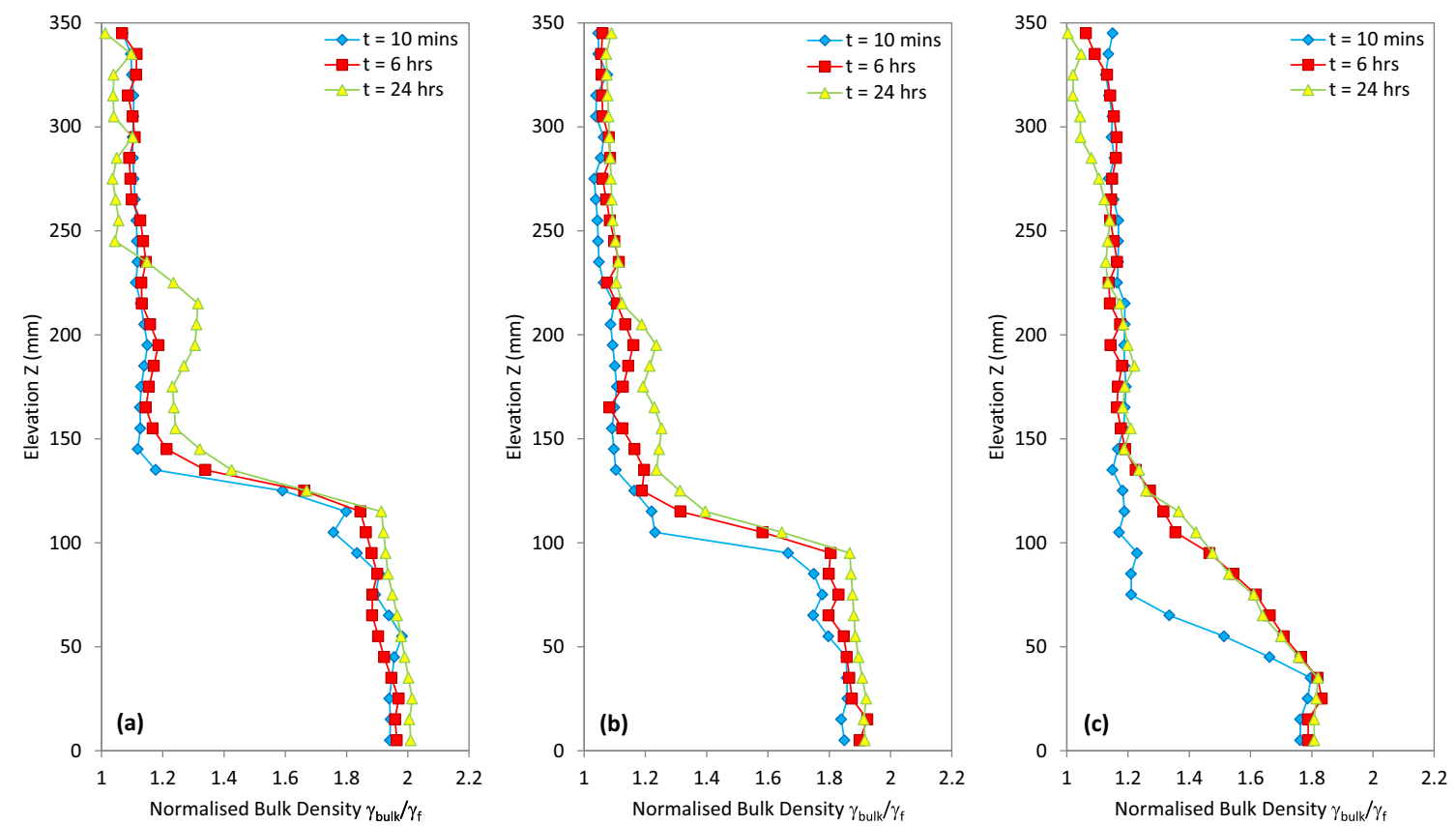

Fig. 8 Longer term temporal development in normalised bulk density $\gamma_{\text {bulk }} / \gamma_{\mathrm{f}}$ profiles at elapsed times shown for runs a ST1 (85s:15c), b ST3 (75s:25c) and c ST5 (65s:35c) (Table 1) 
Fig. 9 Longer term temporal development in normalised bulk density $\gamma_{\text {bulk }} / \gamma_{\mathrm{f}}$ profiles at elapsed times shown for runs a LT2

(75s:25c), b LT3 (50s:50c), c LT4 $(25 \mathrm{~s}: 75 \mathrm{c})$ and $\mathbf{d}$ LT5 (0s:100c)

(Table 1)
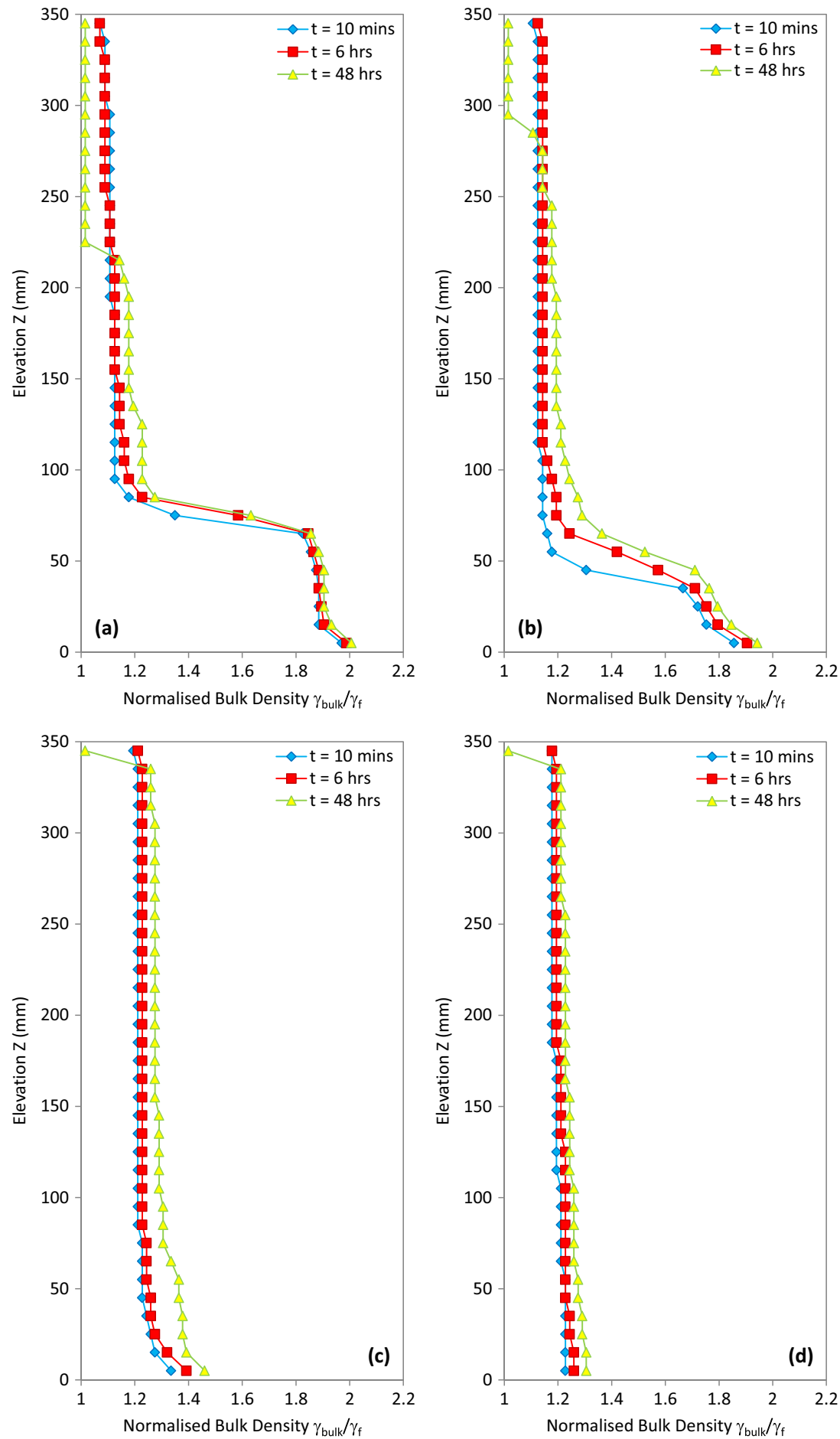

the $85 \mathrm{~s}: 15 \mathrm{c}$ mixture (i.e. run ST1, Table 1) at elapsed times of $10 \mathrm{~min}, 6 \mathrm{~h}$ and $24 \mathrm{~h}$. It is apparent from these profiles that the position of the density interface between the lower sand-dominated layer (i.e. $Z<125 \mathrm{~mm}$ ) and upper clay-dominated layer is established early in the run (i.e. $t<10 \mathrm{~min}$ ) and remains virtually unchanged over the 24-h run duration. The normalised density measurements in the sand-dominated base layer are shown to increase slightly over time [i.e. $\gamma_{\text {bulk }} / \gamma_{\mathrm{f}}=1.88 \rightarrow 1.94$ (on average) as $t=10 \mathrm{~min} \rightarrow 24 \mathrm{~h}$, suggesting that some degree of compaction or grain re-organisation is occurring during this period. It is interesting to note, however, that there is a significant increase in density observed within the upper clay-dominated layer in the region above the sand-clay transition interface (i.e. $Z=135-235 \mathrm{~mm}$ ), where $\gamma_{\text {bulk }} / \gamma_{\mathrm{f}}$ values increase by an average of $13.2 \%$ 
[i.e. $\gamma_{\text {bulk }} / \gamma_{\mathrm{f}}=1.13 \rightarrow 1.28$ (on average) as $t=10 \mathrm{~min} \rightarrow$ $24 \mathrm{~h}$. This is clearly indicative of the formation and initial consolidation of the clay-dominated bed layer above the sand-dominant base layer, which is also highlighted by the $4.6 \%$ net reduction in $\gamma_{\text {bulk }} / \gamma_{\mathrm{f}}$ values at higher elevations within the column (i.e. $Z>245 \mathrm{~mm}$ ) due to hindered settling effects. For the $75 \mathrm{~s}: 25 \mathrm{c}$ mixture (i.e. run ST3, Table 1), similar overall temporal development of the $\gamma_{\text {bulk }} / \gamma_{\text {f }}$ profiles is observed (Fig. 8b) but with a more notable increase in the sand-clay interface elevation between elapsed times $t=10 \mathrm{~min}$ and $t=6 \mathrm{~h}$. This is consistent with the results presented in Fig. 7b, which indicate that a longer elapsed time is required in order to achieve a stable position for the sand-clay transition interface (i.e. $t>600 \mathrm{~s}$ ). It is also interesting to note that the bulk density in the base sand-dominated layer again increases over time but is reduced in the $75 \mathrm{~s}: 25 \mathrm{c}$ mixture due to the increased presence of clay [i.e. $\gamma_{\mathrm{bulk}}$ / $\gamma_{\mathrm{f}}=1.80 \rightarrow 1.89$ (on average) as $t=10 \mathrm{~min} \rightarrow 24 \mathrm{~h}$ ]. The corresponding density profiles for the $65 \mathrm{~s}: 35 \mathrm{c}$ mixture (i.e. run ST5, Table 1) indicate significant changes occur between $t=10 \mathrm{~min}$ and $t=6 \mathrm{~h}$ (Fig. $8 \mathrm{c}$ ). At the base of the column (i.e. $Z<35 \mathrm{~mm}$ ), the density of the sanddominated layer is again slightly reduced and increases only slightly with elapsed time [i.e. $\gamma_{\text {bulk }} / \gamma_{\mathrm{f}}=1.78 \rightarrow$ 1.81 (on average) as $t=10 \mathrm{~min} \rightarrow 24 \mathrm{~h}$ ]. Immediately above this base layer, there is a notable deviation from the well-defined sand-clay interface of the mixtures with higher sand contents (i.e. Fig. 8a, b) to an approximately linear density reduction within a sand-clay transition region [i.e. $\gamma_{\text {bulk }} / \gamma_{\mathrm{f}}=1.82 \rightarrow 1.19$ as $Z=35 \rightarrow 145 \mathrm{~mm}$ (shown for density profiles at both $t=6$ and $24 \mathrm{~h}$ )]. This is clearly indicative of the more transitional segregation (e.g. Figs. 2 b and $3 a$ ) that occurs in mixed sediment bed deposits for sand-clay mixtures containing higher clay contents $\phi_{\mathrm{s}}{ }^{\mathrm{cl}}$, as discussed previously.

Figure 9 indicates similar temporal development (over $48 \mathrm{~h}$ ) in normalised density profiles for sand-clay mixtures with increasing proportions of clay content (i.e. 25, 50, 75 and $100 \%$ clay). Within the $75 \mathrm{~s}: 25 \mathrm{c}$ and $50 \mathrm{~s}: 50 \mathrm{c}$ mixtures (i.e. runs LT2 and LT3, Table 1), Fig. 9a, b reveals similar stratified bed conditions to those developing within Fig. 8b, c (i.e. runs ST3 and ST5, respectively), albeit with sharper transitions between the lower sand-dominated and upper clay-dominated deposit layers. In this regard, it is interesting to note that runs LT2 and LT3 are associated with lower initial clay contents (i.e. $\phi_{\mathrm{s}}{ }^{\mathrm{cl}}=0.032$ and 0.064 , respectively) in the sand-clay mixture, compared to the ST3 and ST5 runs (i.e. $\phi_{\mathrm{s}}{ }^{\mathrm{cl}}=0.054$ and 0.076 , respectively). This, again, suggests that higher clay contents $\phi_{\mathrm{s}}{ }^{\mathrm{cl}}$ in the sand-clay mixtures, to some extent, act to inhibit segregation within the resulting bed deposit. This point is reinforced further by the resulting density profiles for the $25 \mathrm{~s}: 75 \mathrm{c}$ mixture (i.e. run LT4, Table 1), which indicates a general increase in density with time, but no clear segregation in the resulting bed deposit [i.e. $\gamma_{\text {bulk }} / \gamma_{\mathrm{f}}=1.46 \rightarrow$ 1.27 as $Z=5 \mathrm{~mm} \rightarrow 155 \mathrm{~mm}$, Fig. 9c]. When compared directly with the 0s:100c mixture (Fig. 9d), it is clear that the observed increase in measured densities in the lower sedimentation column, for the $25 \mathrm{~s}: 75 \mathrm{c}$ mixture, must be associated with the sand proportion becoming trapped within the claydominated layer without forming a segregated sanddominated bottom deposit layer, due to the high clay content within the initial sand-clay mixture (i.e. $\phi_{\mathrm{s}}{ }^{\mathrm{cl}}=0.095$, run LT4, Table 1). It is interesting to note that the only other run that displayed no layered sand-clay segregation within the resulting bed deposit (i.e. run ST9, Table 1) also had a similarly high clay content (i.e. $\phi_{\mathrm{s}}{ }^{\mathrm{cl}}=0.110$ ), albeit also with a considerably higher sand content (i.e. $\phi_{\mathrm{s}}^{\mathrm{sa}}=0.20$ ) than run LT4 (i.e. $\phi_{\mathrm{s}}^{\mathrm{sa}}=0.031$ ). Images for the resulting deposit from run ST9 (i.e. Fig. 10) indicate that although no sanddominated bottom layer is shown to form, the high sand content becomes trapped in distinct patches within the claydominated layer [most notably for $Z<200 \mathrm{~mm}$ at 6 and 24 h, Fig. 10b, c].

\section{Discussion of results}

\subsection{Sedimentation rates for sand-clay mixtures}

Figure 4 showed the measured sedimentation rates for the various sand-clay mixtures tested from the downward displacement of the upper bed surface interface with the supernatant pore water. In general, the sedimentation behaviour of the different mixtures was as expected, with a clear transition shown between the initial settling regime and subsequent phase 1 consolidation regime (e.g. Fig. 4c). In addition, the anticipated parametric dependence of decreasing settling rates for sand-clay mixtures with higher initial mass concentrations (and, specifically, higher clay mass concentrations $C_{\mathrm{s}}{ }^{\mathrm{cl}}$ ) was generally shown to hold. However, direct comparison of the results for runs ST4 $\left[65 \mathrm{~s}: 35 \mathrm{c} ; C_{\mathrm{s}}{ }^{\mathrm{cl}}=196 \mathrm{~g} \mathrm{l}^{-1}\right.$; salinity $=30 \mathrm{ppt}$ green triangles in Fig. 4a, c] and ST9 [65s:35c; $C_{\mathrm{s}}{ }^{\mathrm{cl}}=285 \mathrm{~g}^{-1}$; salinity $=30 \mathrm{ppt-red} \mathrm{triangles}$ in Fig. $4 \mathrm{a}, \mathrm{c}]$ indicated the opposite trend. In this regard, the key distinguishing feature of the sedimentation behaviour in run ST9 (compared to all other ST runs, Table 1) was that no initial segregation of the sand and clay fractions was observed. Indeed, comparing the upper interface displacements and corresponding sedimentation rates for runs ST4 and ST9 in isolation [panels a and b of Fig. 11, respectively], we observe distinct differences in the transition behaviour. Specifically, although the initial downward interface displacement is similar in both runs for $t=0 \rightarrow 1.5 \mathrm{~h}$ [slightly lower in run ST9, Fig. 11a], after 
Fig. 10 Time-lapsed images of sand-clay bed deposit for run ST9 $(65 \mathrm{~s}: 35 \mathrm{c})$ (Table 1) at elapsed times $t$ shown, indicating no sand and clay layer segregation over the experiment duration

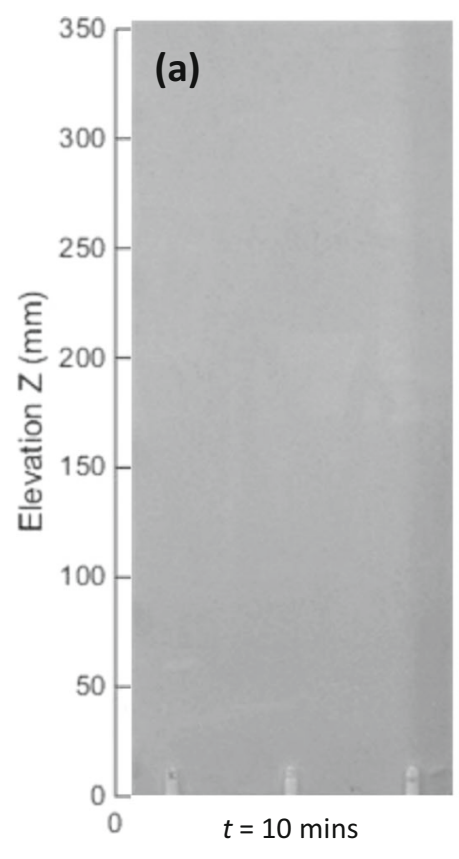

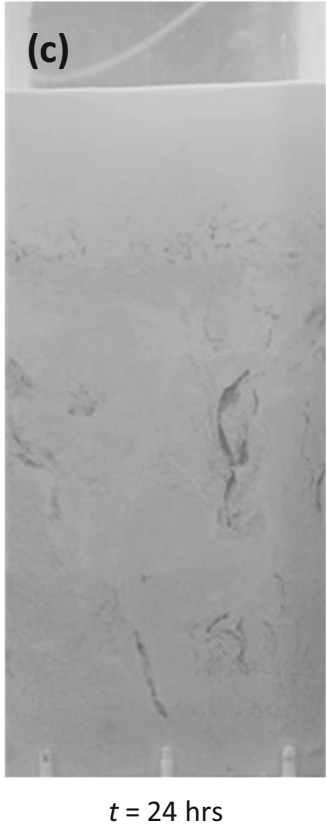

this point, the rate of downward displacement increases sharply in ST9 compared to ST4, which increases at a slower (albeit steady) rate over the period $t=1.5 \rightarrow 3 \mathrm{~h}$
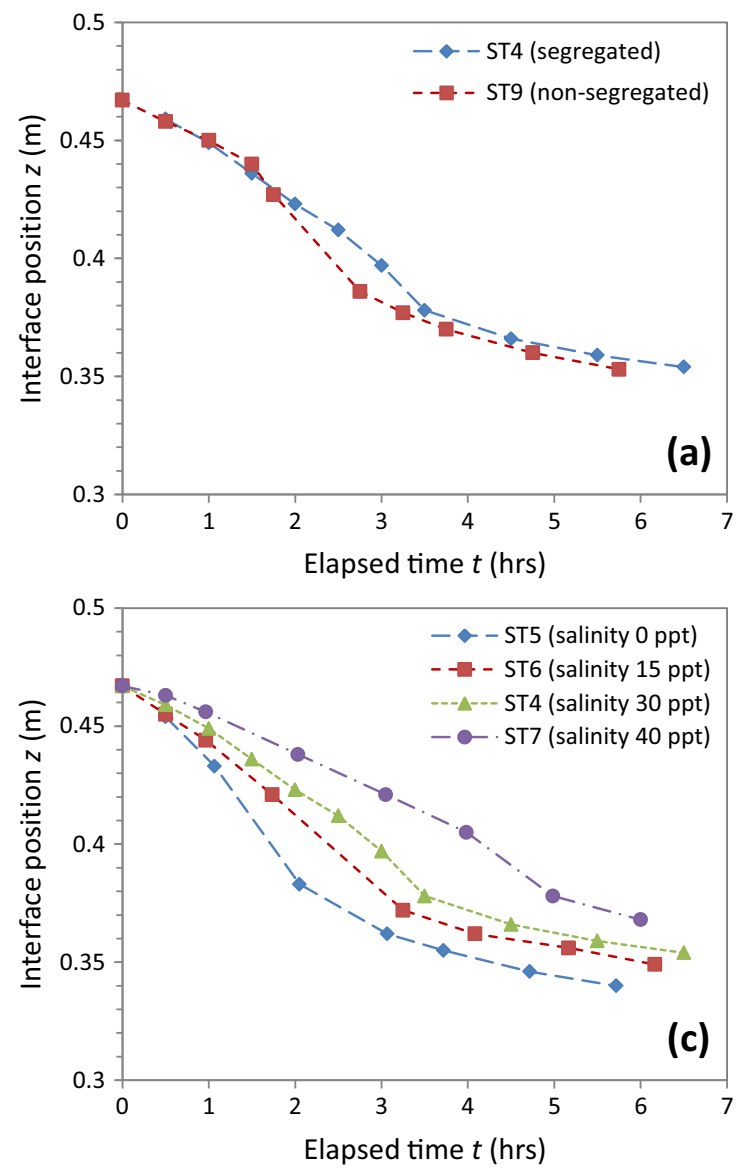

(Fig. 11a). This is reflected in the corresponding sedimentation rates, which show an earlier and higher peak value in ST9 compared to ST4. In this context, it is interesting
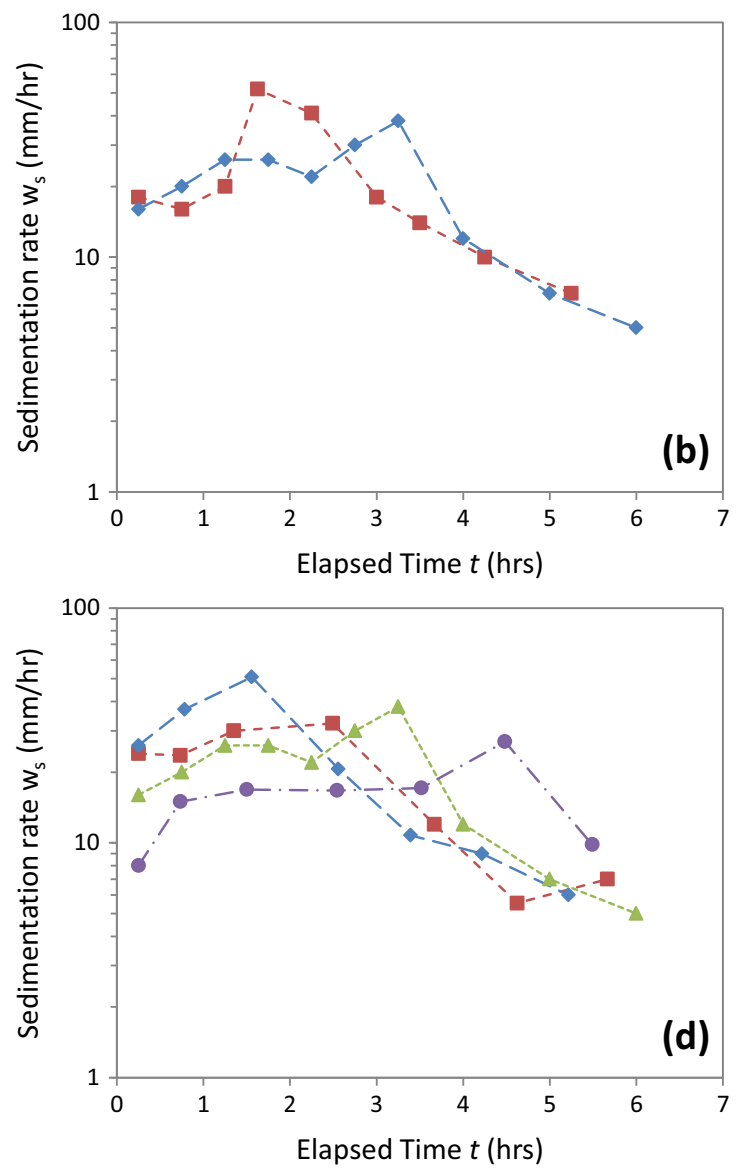

Fig. 11 Comparison of upper interface displacement (a and $\mathbf{c})$ and sedimentation rates (b and $\mathbf{d})$ showing parametric influence of $\mathbf{a}, \mathbf{b}$ segregating/nonsegregating sand-clay mixtures (i.e. runs ST4 and ST9) and c, d pore water salinity (i.e. runs ST4-ST7) 
to note that for sand-clay mixtures demonstrating initial segregation (i.e. through sand deposition to the base of the column), the subsequent settling characteristics and transition to phase 1 consolidation will behave similar to a clay-dominated suspension in the absence of sand (e.g. Fig. 2). What is less clear, however, is when this segregation does not occur (e.g. Fig. 10); what influence does the trapped sand fraction have on the sedimentation rate and how does it affect the transition between the settling regime and the onset of phase 1 consolidation? Indeed, it can be hypothesised whether or not the initial settling regime exists for non-segregating sand-clay mixtures, as the fact that the sand fraction has not segregated clearly suggests that the clay fraction has already reached the gelling concentration. As such, this condition cannot be accounted for in the polydisperse hindered settling model, discussed later in Section 4.3.

The parametric influence of salinity on sedimentation rates (for otherwise identical conditions) is shown (Fig. 4) to result in higher initial settling rates for sandclay mixtures with lower pore water salinities. This trend is clearly demonstrated from the measured temporal displacement of the upper interface for selected runs (i.e. ST4-7, Table 1) with varying pore water salinities (Fig. 11c), and from corresponding sedimentation rates, which indicate larger and earlier peak settling rates occur for sand-clay mixtures with reduced pore water salinities (Fig. 11d). This observed parametric dependence is again somewhat surprising given the expectation that some degree of salinity would be expected to promote flocculation within mud suspensions (e.g. as occurs in brackish estuarine waters) and, hence, result in increased sedimentation rates compared to those obtained in freshwater (Sutherland et al. 2014) [note that the parametric influence of salinity on mud flocculation processes is also known to diminish for salinity values above $\sim 20 \mathrm{ppt}$. A possible reason for this parametric inconsistency may again arise from key differences in the mixture composition within the current experiments compared with previous studies, namely, the very high clay mass concentration range tested (i.e. $C_{\mathrm{S}}^{\mathrm{cl}}=84-285 \mathrm{~g} \mathrm{l}^{-1}$ in ST runs, Table 1). As a comparison, Sutherland et al. (2014) investigated the settling of kaolinite clay suspensions within a mass concentration range $C_{\mathrm{s}}^{\mathrm{cl}}=14.7-39.3 \mathrm{~g} \mathrm{l}^{-1}$ (i.e. up to one order of magnitude lower than the current study), while suspended sediment concentrations occurring in the turbidity maximum zone of estuaries can typically reach up to $\sim 10$ to $\sim 15 \mathrm{~g} \mathrm{l}^{-1}$. Thus, the sand-clay mixtures tested in the current study are more representative of hyper-concentrated, near-bed, fluid-mud layers and, consequently, are expected to display significantly different settling characteristics compared to these more dilute suspensions (which may also account, to some extent, for the different parametric influences on sedimentation rates observed).

Clearly, both these parametric effects (salinity and concentration) need to be examined more closely over a wider range of experimental conditions (i.e. segregating and nonsegregating mixture compositions, mass concentrations and pore water salinities) to establish improved understanding of the transitional sedimentation behaviour changes from dilute suspensions $\rightarrow$ hyper-concentrated fluid muds $\rightarrow$ phase 1 consolidation.

\subsection{Parametric conditions for segregation in sand-clay mixtures}

Within the current settling column experiments, only two sand-clay mixture runs were shown to result in the formation of a fully mixed bed deposit layer (i.e. runs LT4 and ST9, Table 1). Recently, Grasso et al. (2014) proposed for natural sand-mud mixtures that the relative mud concentration $C_{\text {relmud }}$ (i.e. silt/clay content), relative to the volumetric sand content $\phi_{\text {sand }}$ in the mixture, could be used as an indicator of segregation in the resulting deposit, where:

$C_{\text {relmud }}=\frac{C_{\text {mud }}}{1-\phi_{\text {sand }}}$

where $C_{\mathrm{mud}}$ is the mass concentration of mud (i.e. clay/silt). Analysis of previous settling column studies reported in Grasso et al. (2015) for the settling and consolidation of natural sand-mud mixtures suggested that no segregation occurred for $C_{\text {relmud }}>\sim 200 \mathrm{~kg} \mathrm{~m}^{-3}$ (over a wide range of mixture concentrations and sand contents). In the current runs (i.e. Table 1), with the appropriately adopted notation (i.e. $C_{\mathrm{s}}^{\mathrm{cl}}=C_{\mathrm{mud}}$ and $\phi_{\mathrm{s}}^{\mathrm{sa}}=C_{\mathrm{s}}^{\mathrm{sa}} / \gamma_{\mathrm{s}}=\phi_{\text {sand }}$ in Eq. 17), the corresponding values of $C_{\text {relmud }}$ for the idealised sand-clay mixtures tested range from $C_{\text {relmud }}=0$ (i.e. run $\mathrm{LT} 1$, $100 \%$ sand) up to $356 \mathrm{~kg} \mathrm{~m}^{-3}$ (i.e. run ST9, $35 \%$ sand), with the threshold for segregation occurrence lying between $C_{\text {relmud }}=\sim 230 \mathrm{~kg} \mathrm{~m}^{-3}$ (i.e. segregation, runs ST4-7) and $C_{\text {relmud }}=\sim 250 \mathrm{~kg} \mathrm{~m}^{-3}$ (i.e. no segregation, run LT4). This appears to be in broad accord with Grasso et al. (2015) but does not provide further detail of the physical hindered settling processes under which sandclay segregation may or may not occur.

\subsection{Polydisperse model for hindered settling of sand-clay mixtures}

It is informative to consider the potential reciprocal influences that the sand and clay fractions are likely to have on each other in terms of their hindered settling characteristics within the sedimentation column. This is demonstrated through use of a hindered settling model for sand 
particle-clay floc mixtures developed by Cuthbertson et al. (2008). The model is based on a polydisperse formulation from Batchelor (1982), whereby the fractional settling velocities $w_{\mathrm{si}}$ for a suspension containing $m$ different particle types with volumetric concentrations $\phi_{j}$ within the polydisperse mixture can be determined by

$w_{\mathrm{s} i}=w_{\mathrm{s} i, 0}\left(1-\sum_{j=1}^{m} S_{i j} \phi_{j}\right)$

where $w_{\mathrm{s} i, 0}$ is the terminal settling velocity of a solitary particle from fraction $i$ and $S_{i j}$ is an empirical polydisperse sedimentation parameter dependent on (i) the particle size ratio $\lambda_{i j}\left(=d_{j} / d_{i}\right)$, (ii) the reduced density ratio $\gamma_{i j}$ $\left[=\left(\gamma_{j}-\gamma_{\mathrm{f}}\right) /\left(\gamma_{i}-\gamma_{\mathrm{f}}\right)\right]$ and (iii) the particle Péclet number Pe [i.e. Pe» 1 for predominantly advective particle motion and $\mathrm{Pe} \ll 1$ for randomly diffusive (e.g. Brownian) particle motion]. Davis and Gecol (1994) extended this work to consider a Richardson and Zaki (1954) type relation for hindered settling in polydisperse suspensions, such that

$w_{\mathrm{s} i}=w_{\mathrm{s} i, 0}(1-\phi)^{-S_{i i}}\left(1-\sum_{j \neq 1}^{m}\left(S_{i j}-S_{i i}\right) \phi_{j}\right)$

where $\phi$ is the total volumetric concentration of the mixture and $S_{i i}$ is the equivalent empirical sedimentation parameter for a monodisperse suspension. Cuthbertson et al. (2008) applied this polydisperse approach to consider mixed suspensions of uniform-sized sand particles and clay flocs, with hindered settling characteristics, $w_{\mathrm{s}}{ }^{\mathrm{sa}}$ and $w_{\mathrm{s}}^{\text {floc }}$, respectively, given by

$w_{\mathrm{s}}^{\mathrm{floc}}=w_{\mathrm{s}, 0}^{\mathrm{floc}}(1-\phi)^{-S_{\mathrm{ff}}}\left[1+\left(S_{\mathrm{fs}}-S_{\mathrm{ff}}\right) \phi_{\mathrm{s}}^{\mathrm{sa}}\right]$

$w_{\mathrm{s}}^{\mathrm{sa}}=w_{\mathrm{s}, 0}^{\mathrm{sa}}(1-\phi)^{-S_{\mathrm{ss}}}\left[1+\left(S_{\mathrm{sf}}-S_{\mathrm{ss}}\right) \phi_{\mathrm{floc}}\right]$

Here, the total mixture volumetric concentration $\phi=\left(\phi_{\text {floc }}+\phi_{\mathrm{s}}{ }^{\mathrm{sa}}\right)$, with the volumetric clay floc concentration $\phi_{\text {floc }}$ given by (Winterwerp 2002):

$\phi_{\text {floc }}=\left(\frac{\gamma_{\mathrm{s}}-\gamma_{\mathrm{f}}}{\gamma_{\mathrm{floc}}-\gamma_{\mathrm{f}}}\right) \frac{C_{\mathrm{s}}}{\gamma_{\mathrm{s}}}=\frac{C_{\mathrm{s}}}{\gamma_{\mathrm{s}}}\left(\frac{d_{\mathrm{floc}}}{d_{\mathrm{s}}^{\mathrm{cl}}}\right)^{3-n_{\mathrm{f}}}$

where $C_{\mathrm{s}}$ is the solid (i.e. sand and clay) mass concentration $\left(\mathrm{kg} \mathrm{m}^{-3}\right) ; \gamma_{\mathrm{s}}\left(=\gamma_{\mathrm{s}}^{\mathrm{sa}}=\gamma_{\mathrm{s}}^{\mathrm{cl}}\right)$ is the solid particle density; $d_{\mathrm{s}}^{\mathrm{cl}}$ and $d_{\text {floc }}$ are the clay primary particle and flocs sizes, respectively; and $n_{\mathrm{f}}$ is the fractal dimension of the flocs (taken here as $n_{\mathrm{f}}=2.0$ ). Equations 20 and 21 include implicitly all induced hindered settling effects including return flow generation, increased viscosity and buoyancy of the sand-clay mixture (Winterwerp 2002). However, a further correction is required to these fractional hindered settling expressions to account for the increased buoyancy effect resulting from the sum of the volumetric particle concentrations $\phi_{\mathrm{s}}=\left(\phi_{\mathrm{s}}{ }^{\mathrm{sa}}+\phi_{\mathrm{s}}{ }^{\mathrm{cl}}\right)$ rather than from the total mixture volumetric concentration $\phi=\left(\phi_{\text {floc }}+\right.$ $\left.\phi_{\mathrm{s}}^{\mathrm{sa}}\right)$, i.e.:

$w_{\mathrm{s}}^{\mathrm{floc}}=w_{\mathrm{s}, 0}^{\mathrm{floc}}(1-\phi)^{-\left(S_{\mathrm{ff}}+1\right)}\left(1-\phi_{\mathrm{s}}^{\mathrm{cl}}-\phi_{\mathrm{s}}^{\mathrm{sa}}\right)\left[1+\left(S_{\mathrm{fs}}-S_{\mathrm{ff}}\right) \phi_{\mathrm{s}}^{\mathrm{sa}}\right]$

$w_{s}^{s a}=w_{s, 0}^{s a}(1-\phi)^{-\left(S_{s s}+1\right)}\left(1-\phi_{s}^{c l}-\phi_{s}^{s a}\right)\left[1+\left(S_{s f}-S_{s s}\right) \phi_{f l o c}\right]$

Within Eqs. 20, 21, 23 and 24, the sedimentation parameters $S_{\mathrm{fs}}$ and $S_{\mathrm{sf}}$ for the clay floc and sand particle fractions, respectively, can be specified (following Ha and Lui 2002) as:

$S_{\mathrm{fs}}=-2.5-\left(\lambda_{\mathrm{fs}}^{2}+3 \lambda_{\mathrm{fs}}+1-\frac{1.87 \lambda_{\mathrm{fs}}}{1+0.0024 \lambda_{\mathrm{fs}}^{2}}\right) \gamma_{\mathrm{fs}}$

$S_{\mathrm{sf}}=-2.5-\left(\lambda_{\mathrm{sf}}^{2}+3 \lambda_{\mathrm{sf}}+1-\frac{1.87 \lambda_{\mathrm{sf}}}{1+0.0024 \lambda_{\mathrm{sf}}^{2}}\right) \gamma_{\mathrm{sf}}$

where particle size ratios $\lambda_{\mathrm{fs}}=d_{\mathrm{s}}^{\mathrm{sa}} / d_{\text {floc }}$ and $\lambda_{\mathrm{sf}}=d_{\text {floc }} / d_{\mathrm{s}}$ sa, while reduced density ratios $\gamma_{\mathrm{fs}}=\left(\gamma_{\mathrm{s}}-\gamma_{\mathrm{f}}\right) /\left(\gamma_{\mathrm{floc}}-\gamma_{\mathrm{f}}\right)$ and $\gamma_{\mathrm{sf}}=\left(\gamma_{\mathrm{floc}}-\gamma_{\mathrm{f}}\right) /\left(\gamma_{\mathrm{s}}-\gamma_{\mathrm{f}}\right)$. Corresponding monodisperse sedimentation parameters $S_{\mathrm{ff}}=S_{\mathrm{ss}}(=5.63)$ are also obtained from Eqs. 25 and 26 by assuming the particle size, and reduced density ratios are $\lambda=1$ and $\gamma=1$, respectively.

Thus, Eqs. 23 and 24 can be used to determine the relative hindered settling rates for the sand particle and clay floc fractions of the sediment mixture. [For full details on the development of the polydisperse hindered settling model for sandmud (i.e. clay) mixtures, see Cuthbertson et al. (2008)]. It is proposed in this current analysis that mixture conditions under which no sand-clay segregation occurs will result when the initial clay concentration $C_{\mathrm{s}}^{\mathrm{cl}}$ is close to (or at) the gelling concentration $C_{\mathrm{gel}}$. This condition occurs when the volumetric floc concentration $\phi_{\text {floc }} \rightarrow 1$ (i.e. Winterwerp 2002) and, hence, from Eq. 22, we get:

$C_{\mathrm{s}}^{\mathrm{cl}}=C_{\mathrm{gel}}=\gamma_{\mathrm{s}}\left(\frac{d_{\mathrm{s}}^{\mathrm{cl}}}{d_{\mathrm{floc}}}\right)^{3-n_{\mathrm{f}}}$

For the purposes of this analysis, it is assumed that $C_{\text {gel }}=330 \mathrm{~kg} \mathrm{~m}^{-3}$ [i.e. corresponding to the largest clay mass concentration $C_{\mathrm{s}}^{\mathrm{cl}}=330 \mathrm{~kg} \mathrm{~m}^{-3}$ tested within the experimental runs (LT5, Table 1)], with $\gamma_{\mathrm{s}}=2590 \mathrm{~kg} \mathrm{~m}^{-3}, n_{\mathrm{f}}=2.0$ and $d_{\mathrm{s}}^{\mathrm{cl}}=2 \mu \mathrm{m}$ (i.e. $d_{50}$ ). [Note that in reality, this gelling concentration may be considerably lower but is known to depend on parameters such as fluid shear rate $G$ and the fractal dimension $n_{\mathrm{f}}$ of the clay/mud flocs generated (Winterwerp and van Kesteren 2004), which are either undefined or assumed within the current study]. Re-arranging Eq. 27 yields a floc size $d_{\text {floc }}=15.6 \mu \mathrm{m}$, which is adopted as the representative clay floc size generated within the sedimentation column runs for the current hindered settling analysis.

Figure 12 shows the predicted non-dimensional hindered settling characteristics $w_{\mathrm{s}}^{\mathrm{sa}} / w_{\mathrm{s}, 0}{ }^{\mathrm{sa}}$ and $w_{\mathrm{s}}^{\text {floc }} / w_{\mathrm{s}, 0}{ }^{\text {floc }}$ for the 
Fig. 12 Predicted nondimensional hindered (sand-clay) settling characteristics $w_{\mathrm{ss}} / w_{\mathrm{ss}, 0}$ and $w_{\mathrm{sf}} \mathrm{f} w_{\mathrm{sf}, 0}$ versus volumetric mixture concentration $\phi$ (for volumetric sand particle concentration $\phi_{\mathrm{s}}$ values shown) Discrete data points show predicted $w_{\mathrm{ss}} / w_{\mathrm{ss}, 0}$ and $w_{\mathrm{sf}} / w_{\mathrm{sf}, 0}$ values for runs LT2-LT4 and ST1-ST9 (see Table 1)

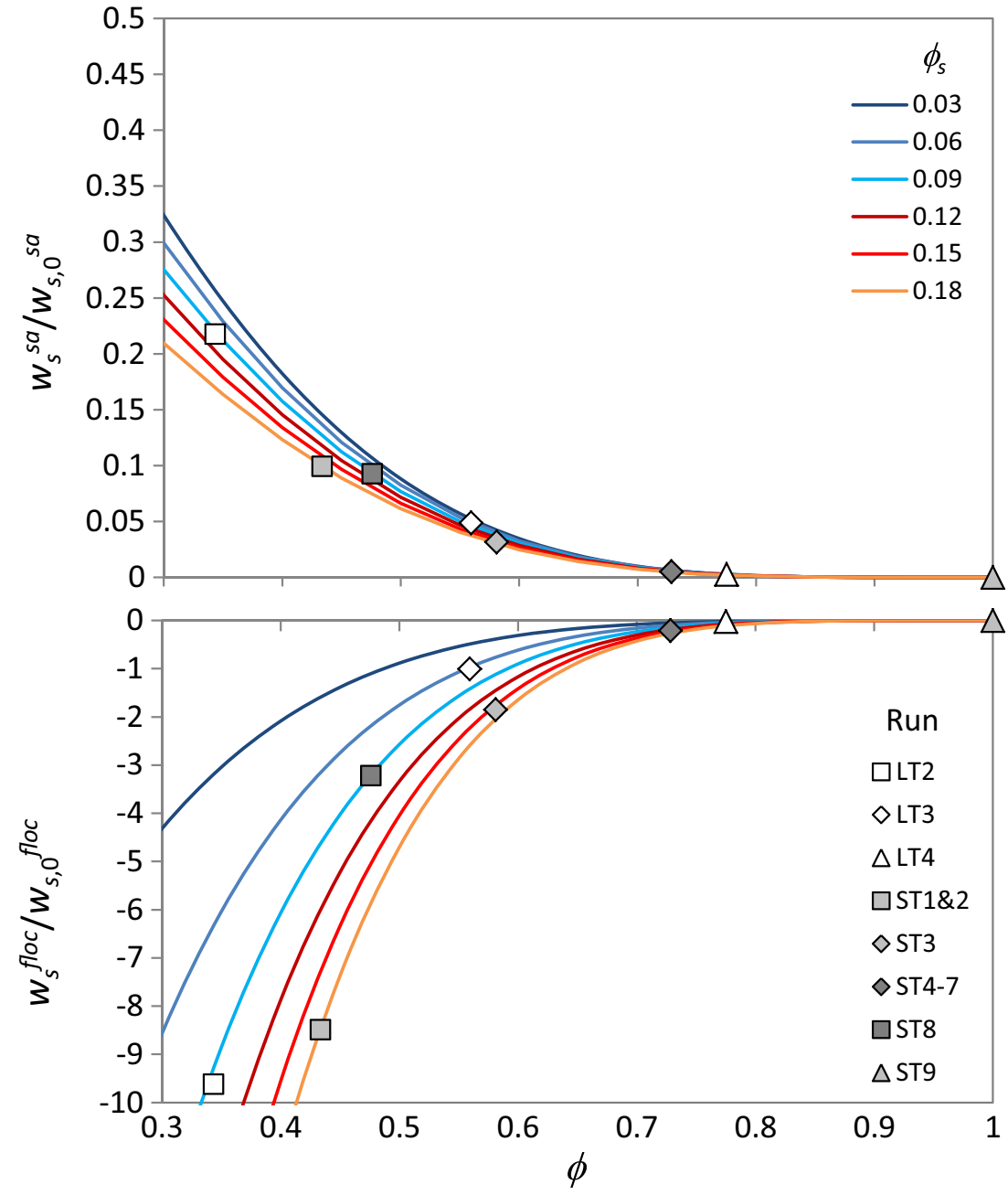

sand particles and clay flocs (Eqs. 23 and 24, respectively), for a range of volumetric mixture concentrations $\phi=0.3-1.0$ (and volumetric sand particle concentrations $\left.\phi_{\mathrm{s}}^{\mathrm{sa}}=0.03-0.18\right)$. The predicted hindered settling regime of the sand fraction (Eq. 24) varies between $w_{\mathrm{s}}^{\mathrm{sa}} / w_{\mathrm{s}, 0}{ }^{\mathrm{sa}}=0.22-0.33$ at $\phi=0.3$ (depending of $\phi_{\mathrm{s}}$ values), reducing to $w_{\mathrm{s}}{ }^{\mathrm{sa}} / w_{\mathrm{s}, 0}{ }^{\mathrm{sa}}=0$ at $\phi=1$ (for all $\phi_{\mathrm{s}}^{\mathrm{sa}}$ values). By contrast, the corresponding hindered regime for the clay flocs (Eq. 22) is negative for all $\phi$ values, with $w_{\mathrm{s}}{ }^{\text {floc }} / w_{\mathrm{s}, 0}$ floc values of about up to -10 at $\phi$ values between 0.3 and 0.4 (again depending on $\phi_{\mathrm{s}}{ }^{\text {sa }}$ values). These negative values suggest that the clay flocs in the sedimentation column are displaced upwards due to strong return flow effects generated by the hindered settling of the sand fraction. Indeed, larger sand concentrations are shown to result in a stronger upward motion within the clay flocs. By contrast, larger clay concentrations $\phi_{\mathrm{s}}{ }^{\mathrm{cl}}$ within the mixture (i.e. increased $\phi$ for given $\phi_{\mathrm{s}}^{\mathrm{sa}}$ ) are shown to reduce the upward motion of flocs and increase the hindered settling of sand particles, with the limit $w_{\mathrm{s}}{ }^{\text {floc }} / w_{\mathrm{s}, 0}{ }^{\text {floc }} \rightarrow w_{\mathrm{s}}{ }^{\mathrm{sa}} / w_{\mathrm{s}, 0}{ }^{\mathrm{sa}} \rightarrow 0$ as $\phi \rightarrow 1$ (Fig. 12). It is therefore proposed that the generation of clearly segregated sand- and clay-dominated deposit layers in the column from initially well-mixed sand-clay suspensions requires the clay fraction (i.e. flocs) to be displaced upwards within the column while the sand fraction (i.e. particles) settles to the base of the column.

In this regard, the individual data points plotted on Fig. 12 show the predicted $w_{\mathrm{s}}^{\mathrm{sa}} / w_{\mathrm{s}, 0}$ sa and $w_{\mathrm{s}}^{\text {floc }} / w_{\mathrm{s}, 0}{ }^{\text {floc }}$ values (Eqs. 23 and 24) for all sand-clay mixture conditions tested in the column (see Table 1). It is shown that sand-clay mixtures with lower volumetric concentrations $\phi<0.5$ (i.e. runs LT2 and ST1, 2 and 8, Fig. 12) have the largest predicted difference between hindered sand particle settling (i.e. $w_{\mathrm{s}}{ }^{\mathrm{sa}} / w_{\mathrm{s}}$, ${ }_{0}^{\mathrm{sa}} \approx 0.1 \rightarrow 0.25$ ) and the upward clay floc motion (i.e. $w_{\mathrm{s}}^{\text {floc }}$ $w_{\mathrm{s}, 0}{ }_{\text {floc }} \approx-3.5 \rightarrow-10$ ). These runs are also shown to generate the greatest degree of sand-clay layer segregation (and most well-defined interface) in the resulting bed deposit (e.g. Figs. 2a and 3ii). Sand-clay mixtures in the range $\phi \approx 0.55 \rightarrow 0.75$ (i.e. runs LT3 and ST3-7, Fig. 12) have lesser predicted differences between hindered sand particle settling (i.e. $w_{\mathrm{s}}{ }^{\mathrm{sa}} / w_{\mathrm{s}, 0}{ }^{\mathrm{sa}} \approx 0.01 \rightarrow 0.05$ ) and upward floc motion (i.e. $\left.w_{\mathrm{s}}^{\text {floc }} / w_{\mathrm{s}, 0}{ }^{\text {floc }} \approx-0.2 \rightarrow-2\right)$. These mixtures correspond to conditions under which more transitional sand-clay segregation 
occurs in the resulting bed deposit [i.e. with less well-defined interface between the sand- and clay-dominated layers, Figs. $2 \mathrm{~b}$ and 3i]. Finally, the two sand-clay mixtures with $\phi>0.75$ (i.e. runs LT4 and ST9, Fig. 12) have the least difference in predicted settling rates between the clay and sand fractions (i.e. $w_{\mathrm{s}}^{\text {floc }} / w_{\mathrm{s}, 0}{ }^{\text {floc }} \approx w_{\mathrm{s}}{ }^{\mathrm{sa}} / w_{\mathrm{s}, 0}$ sa $\rightarrow 0$ as $\phi \rightarrow 1$ ) and correspond to resulting bed deposit conditions where no vertical sand-clay segregation is observed (e.g. Fig. 10b, c).

It is informative to estimate the time scales over which this sand-clay segregation process occurs within the settling column for different mixture conditions. Firstly, however, the settling rates for a single sand particle $\left(d_{\mathrm{s}}^{\mathrm{sa}}=150 \mu \mathrm{m}\right)$ and clay floc $\left(d_{\text {floc }}=15.6 \mu \mathrm{m}\right)$ can be estimated from standard expressions by Cheng (1997) and Winterwerp (2002), respectively, as $w_{\mathrm{s}, 0}{ }^{\mathrm{sa}} \approx 20 \mathrm{~mm} \mathrm{~s}^{-1}$ and $w_{\mathrm{s}, 0}$ floc $\approx 0.6 \mathrm{~mm} \mathrm{~s}^{-1}$. If it is assumed that the nominal interface between the sand-dominated base layer and clay-dominated upper layer forms at elevation $z_{\text {int }}$ (shown schematically in Fig. 13), an indicative time scale $t_{\text {seg }}$ for the sand-clay segregation process can be estimated either from the hindered sand particle settling time, or clay floc rise time, over $z=0.5 h$ between the "centres of mass" of these two layers, i.e.:

$t_{\mathrm{seg}} \approx \frac{0.5 h}{\left|w_{\mathrm{s}}^{\mathrm{sa}}\right|}$ or $t_{\mathrm{seg}} \approx \frac{0.5 h}{\left|w_{\mathrm{s}}^{\text {floc }}\right|}$

where $h$ is the total settling column height. For sand-clay mixtures that lead to highly segregated layered bed deposits (e.g. run ST1 and 2, Table 1), the interface elevation is shown to form at $z_{\text {int }} \approx 0.125 \mathrm{~m}=0.25 \mathrm{~h}$ (i.e. Figs. $5 \mathrm{a}$ and $7 \mathrm{a}$ ). From Fig. 12, the corresponding hindered sand particle settling velocity $w_{\mathrm{s}}{ }^{\mathrm{sa}}$ and upward floc motion $w_{\mathrm{s}}$ floc are predicted as $w$ $\mathrm{s}^{\mathrm{sa}} \approx 0.1 \times w_{\mathrm{s}, 0}{ }^{\mathrm{sa}}=2.0 \mathrm{~mm} \mathrm{~s}^{-1}$ and $w_{\mathrm{s}}{ }^{\text {floc }} \approx-8.5 \times w_{\mathrm{s}}$, $0_{0}^{\text {floc }}=-5.1 \mathrm{~mm} \mathrm{~s}^{-1}$, respectively. Hence, from Eq. 28, the estimated segregation time scales can be calculated as $t$ $\mathrm{seg}=0.5 \mathrm{~h} / \mathrm{w}_{\mathrm{s}}^{\mathrm{sa}}=125 \mathrm{~s}$ and $t_{\mathrm{seg}}=0.5 \mathrm{~h} / \mathrm{w}_{\mathrm{s}}^{\text {floc }}=49 \mathrm{~s}$, the former of which is in broad agreement with the observed time scale of the dense sand base layer formation [i.e. $t=120-140 \mathrm{~s}$, Figs. 2a, 5a and 7a]. Similarly, for sand-clay mixtures resulting in more transitional segregation within the bed (e.g. runs ST4-7, Table 1), Fig. 12 is used to predict $w$ $\mathrm{s}^{\mathrm{sa}} \approx 0.005 \times w_{\mathrm{s}, 0}^{\mathrm{sa}}=0.1 \mathrm{~mm} \mathrm{~s}^{-1}$ and $w_{\mathrm{s}}^{\text {floc }} \approx-0.215 \times w_{\mathrm{s}}$, ${ }_{0}^{\text {floc }}=-0.13 \mathrm{~mm} \mathrm{~s}^{-1}$, with corresponding segregation time scales (Eq. 28) of $t_{\mathrm{seg}} \approx 2500$ and $1920 \mathrm{~s}$, respectively (i.e. $32-42 \mathrm{~min}$ ). This is again shown to be in relatively good agreement with the observed time scale over which the transitional segregation process occurs [i.e. $t=30-60 \mathrm{~min}$, Figs. $2 \mathrm{~b}$ and $5 \mathrm{c}]$. It is worth noting that this initial segregation time scale $t_{\text {seg }}$ is considerably shorter than the overall hindered settling time scale (i.e. $t=9000 \rightarrow 18,000 \mathrm{~s}$ ) prior to the onset of phase I consolidation in the upper clay-dominated bed layer [as indicated in Fig. 4c].
In summary, the polydisperse hindered settling approach for sand-clay mixtures, proposed by Cuthbertson et al. (2008), provides improved representation of the physical mechanisms and reciprocal interactions between the sand and clay fractions that can lead to segregation within the bed deposit. In addition, it provides new understanding of the parametric influences on these bed segregation patterns (e.g. sharp and transitional sand-clay interfaces) as well as information on the time scales over which this segregation would be expected to occur.

\section{Summary and concluding remarks}

The sedimentation behaviour of mixed (sand-clay) sediment suspensions has been examined within parametric settling column experiments employing non-intrusive electrical resistivity profile measurements and time-lapsed imaging to characterise both the temporal and spatial evolution of the resulting bed deposits. The results indicate that segregated bed deposits are generally obtained for the range of sand-clay mixtures tested, with a sand-dominated layer deposited at the column base and subsequently overlain by a clay-dominated layer. The degree of segregation within these deposits is well described by the nature of the interface forming between these two layers, with a sharp, well-defined interface obtained for mixtures with lower clay concentrations $\left(\phi_{\mathrm{s}}{ }^{\mathrm{cl}} \leq 0.05\right)$ and a more transitional interfacial region developing for mixtures with higher clay concentrations $\left(0.054<\phi_{\mathrm{s}}{ }^{\mathrm{cl}}<0.076\right)$. For some mixtures with sufficiently high clay concentrations $\left(\phi_{\mathrm{s}}^{\mathrm{cl}}>0.095\right)$, no sand-clay layer segregation is shown to develop in the resulting bed deposit, irrespective of the corresponding sand concentration $\phi_{\mathrm{s}}^{\text {sa }}$.

The temporal changes in these sand-clay deposition characteristics are successfully identified by the time series electrical resistivity profile measurements taken throughout the duration of each run. Indeed, the experiments clearly demonstrate the success of this non-invasive technique in the fineresolution measurement of mixed sedimentation processes and (dis)continuities within the resulting bed layer deposits (i.e. density, porosity and composition), following appropriate calibrations. Furthermore, the time evolution of the upper clay-water interface (i.e. via time-lapsed images) also provides information on the transition from hindered settling and phase 1 consolidation within the upper clay-dominant bed layer, with the latter process shown to be well-represented by an existing consolidation model (Merckelbach 2000).

In order to investigate the physical mechanisms under which sand-clay bed segregation may (or may not) occur, the polydisperse model of Cuthbertson et al. (2008) is used to predict the relative motion of sand particles and clay flocs during the sedimentation process and how these vary for the different mixture compositions. Specifically, the model 
Fig. 13 Schematic representation of relative sand and clay fraction motion within initial mixture to develop a fully segregated sandclay bed deposit layers and $\mathbf{b}$ transitional segregated sand-clay bed deposit layers

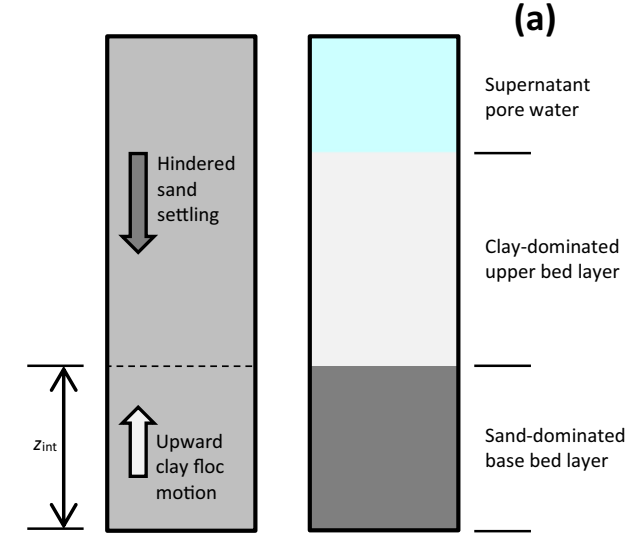

(b)

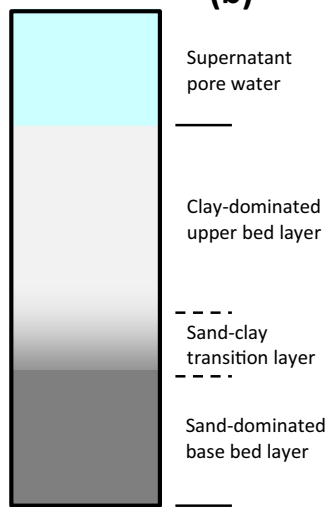

predicts that hindered settling characteristics (i.e. $0 \leq w_{\mathrm{s}}{ }^{\mathrm{sa}} / w_{\mathrm{s}}$, $0^{\mathrm{sa}}<1$ ) will occur for the sand particles, while the clay flocs will be subjected to upward motion (i.e. $w_{\mathrm{s}}^{\text {floc }} / w_{\mathrm{s}, 0}$ floc $\leq 0$ ) due to return flow effects from the settling sand fraction (Fig. 12). The magnitude of the difference between these downward (sand) and upward (clay) motions is found to correlate qualitatively with the degree of sand-clay segregation observed within the resulting bed deposit. Specifically, well-defined segregation between the sand and clay bed layers is observed for mixtures with high sand $\phi_{\mathrm{s}}^{\mathrm{sa}}$ and low clay contents $\phi_{\mathrm{s}}{ }^{\mathrm{cl}}$, where the difference in predicted fractional motions is maximal (see Fig. 12). By contrast, more transitional sand-clay layer segregation occurs for mixtures with higher clay contents $\phi_{\mathrm{s}}^{\mathrm{cl}}$, where this difference in fractional motion is reduced, while no sand-clay layer segregation is observed when the overall mixture concentration $\phi \rightarrow 1$ [i.e. at the so-called gelling concentration, Winterwerp and van Kesteren (2004)]. Furthermore, time scales associated with these well-defined or transitional segregation processes, also estimated from the model predictions of relative sand-clay motions, are shown to agree quantitatively with experimental observations of layer development in the resulting bed deposits.

For these combined experimental measurements and polydisperse model predictions, the physical processes under which sand-clay segregation occurs (shown schematically in Fig. 13) can be described qualitatively as follows: (i) for mixtures with lower clay concentrations $\left(\phi_{\mathrm{s}}{ }^{\mathrm{cl}} \leq 0.05\right)$ : hindered settling of the sand fraction (and strong upward displacement of mud flocs) occurs prior to the clay fraction in the mixture reaching gelling conditions - the resulting deposit forms distinct sand and clay layers separated by a clearly defined interface (Fig. 13a); (b) for mixtures with higher clay concentrations $\left(0.054<\phi_{\mathrm{s}}{ }^{\mathrm{cl}}<0.076\right)$ : the increasingly hindered (i.e. reduced) sand settling rates (and reduced upward displacement of clay flocs) allow a greater proportion of clay to remain trapped in the developing sand-dominated base layer, while the clay fraction above this layer reaches gelling point before the sand fraction is completely deposited - the resulting deposit forms a transitional segregation region (Fig. 13b) where sand particles are trapped in patches within the claydominated matrix (see Figs. $2 \mathrm{~b}$ and 3 ); and (c) for mixtures with very high clay concentrations $\left(\phi_{\mathrm{s}}{ }^{\mathrm{cl}} \geq 0.095\right)$ : very little or no motion is predicted for either fractions suggesting that the mixture is close to or at the gelling point under initial conditions (i.e. prior to sedimentation) - the resulting deposit therefore shows no layer segregation, with the sand fraction trapped almost immediately within the developing clay matrix.

In summary, the study has successfully employed new noninvasive electrical resistivity measurements and time-lapsed image techniques, along with predictions from an existing polydisperse hindered settling model (Cuthbertson et al. 2008) to investigate sedimentation and bed formation processes for mixed (sand-clay) suspensions. This study has highlighted the parametric conditions under which sand-clay segregation can occur in the resulting bed deposits, as well as providing a physical explanation for both the nature and time scale of this segregation. It should be noted here that the predictions obtained from the polydisperse model are based solely on the initial sand-clay mixture conditions and thus do not take account of temporal changes in sand or clay concentrations within the column during the sedimentation process itself. However, the correlation between the predicted hindered sand settling and/or upward clay motion and the time scales over which well-defined or transitional layer segregation occurs within the bed deposit layers appears to provide validation of the polydisperse model predictions (for the first time).

Finally, it is worth noting that the current study is clearly idealised both in terms of the cohesive and non-cohesive sediments used (i.e. $100 \%$ kaolinite and superfine, high silica sand) and the environmental conditions under which the mixed sedimentation processes are studied. Further studies are therefore needed to validate the findings of this study for natural estuarine or coastal sediment deposits, which are characterised by larger ranges of particle sizes, mineralogical compositions and organic fractions. 
Acknowledgments This experimental work in this study was supported by RCUK funding through the Engineering and Physical Sciences Research Council's First Grant Scheme (EPSRC EP/K015117/1), while specialist laboratory equipment for the study was funded through a Research Grant from The Royal Society (RG120540). The authors are also grateful for the comments provided by two anonymous reviewers and the editor that have led to significant improvements in the paper.

Open Access This article is distributed under the terms of the Creative Commons Attribution 4.0 International License (http:// creativecommons.org/licenses/by/4.0/), which permits unrestricted use, distribution, and reproduction in any medium, provided you give appropriate credit to the original author(s) and the source, provide a link to the Creative Commons license, and indicate if changes were made.

\section{References}

Archie GE (1942) The electrical resistivity log as an aid in determining some reservoir characteristics. Trans Am Inst Mining Metall Engr 147:54-62

Atkins ER, Smith GH (1961) The significance of particle shape in formation resistivity factor-porosity relationships. Trans Am Inst Mining Metall Engrs 222:285-291

Bartholomeeusen G, Sills GC, Znidarcic D et al (2002) Sidere: numerical prediction of large-strain consolidation. Geotechnique 52(9):639-648

Batchelor GK (1982) Sedimentation in a dilute polydisperse system of interacting spheres: 1. General theory. J Fluid Mech 119:379-408

Been K, Sills GC (1981) Self-weight consolidation of soft soils: an experimental and theoretical study. Geotechnique 31(4):519-535

Blewett J, McCarter WJ, Chrisp TM, Starrs G (2001) Monitoring sedimentation of a clay slurry. Geotechnique 51(8):723-728

Blewett J, McCarter WJ, Chrisp TM, Starrs G (2003) An experimental study on ionic migration through saturated kaolin. Eng Geol 70(3/4):281-291

Boyce RE (1968) Electrical resistivity of modern marine sediments from the Bering Sea. J Geophys Res 73(14):4759-4766

Cheng NS (1997) Effect of concentration on settling velocity of sediment particles. J Hydrol Eng 123(8):728-731

Cuthbertson AJS, Dong P, King S, Davies PA (2008) Hindered settling velocity of cohesive/non-cohesive sediment mixtures. Coast Eng 55: 1197-1208

Cuthbertson AJS, Dong P, Davies PA (2010) Non-equilibrium flocculation characteristics of fine-grained sediment in grid-generated turbulent flow. Coast Eng 57:447-460

Davis RH, Gecol H (1994) Hindered settling function with no empirical parameters for polydisperse suspensions. AIChE J 40:570-575

Gibson RE, England GL, Hussey MJL (1967) The theory of onedimensional consolidation of saturated clays. Geotechnique 17(3): 262-273

Glover PWJ (2010) A generalized Archie's law for $n$ phases. Geophysics 75(6):E247-E265

Grasso F, Le Hir P, Bassoullet P (2014) Analysis of mixed-sediment consolidation experiments. Proc. 13th Journées Nationales Génie Côtier - Génie Civil, Dunkerque, France

Grasso F, Le Hir P, Bassoullet P (2015) Numerical modelling of mixedsediment consolidation. Ocean Dyn 65:607-616

Ha Z, Lui S (2002) Settling velocities of polydisperse concentrated suspensions. Can J Chem Eng 80:783-790

Ha HK, Maa JPY, Holland CW (2010) Acoustic density measurements of consolidating cohesive sediment beds by means of non-intrusive "Micro-Chirp" acoustic system. Geo-Mar Lett 30(6):585-593

Hayley K, Bentley LR, Gharibiand M, Nightingale M (2007) Low temperature dependence of electrical resistivity: Implications for near surface geophysical monitoring. Geophys Res Lett 34(18):1-5
Khalil MA, Santos FAM (2011) Influence of degree of saturation in the electric resistivity-hydraulic conductivity relationship. In: Dikinya $\mathrm{O}$ (ed) Developments in hydraulic conductivity research, 49-70, InTech, ISBN 978-953-307-470-2 (282p)

Le Hir P, Cayocca F, Waeles B (2011) Dynamics of sand and mud mixtures: a multiprocess-based modelling strategy. Cont Shelf Res 31(10):S135-S149

Manning AJ, Baugh JV, Spearman JR, Whitehouse RJS (2010) Flocculation settling characteristics of mud: sand mixtures. Ocean Dyn 60:237-253

Manning AJ, Baugh JV, Spearman JR, Pidduck EL, Whitehouse RJS (2011) The settling dynamics of flocculating mud-sand mixtures: part 1-empirical algorithm development. Ocean Dyn 61(2-3):311-350

McCarter WJ, Blewett J, Chrisp TM, Starrs G (2005) Electrical property measurements using a modified hydraulic oedometer. Can Geotech J 42:655-662

Merckelbach LM (2000) Consolidation and strength evolution of soft mud layers. PhD thesis, Delft University of Technology

Merckelbach LM, Kranenburg C (2004a) Determining effective stress and permeability equations for soft mud from simple laboratory experiments. Geotechnique 54(9):581-591

Merckelbach LM, Kranenburg C (2004b) Equations for effective stress and permeability of soft mud-sand mixtures. Geotechnique 54(4): 235-243

Pham Van Bang D, Lefrançois E, Sergent P, Bertrand F (2008) MRI experimental and finite elements modelling of the sedimentationconsolidation of mud. La Houille Blanche 3:39-44

Ponziani M, Slob EC, Ngan-Tillard DJM (2012) Experimental validation of a model relating water content to the electrical conductivity of peat. Eng Geol 129-130:48-55

Revil A, Eppehimer JD, Skold M et al (2013) Low-frequency complex conductivity of sandy and clayey materials. J Colloid Interface Sci 398:193-209

Richardson JF, Zaki WN (1954) Sedimentation and fluidisation: part 1 Trans Inst Chem Engr 32(1):35-53

Sutherland BR, Barrett KJ, Gingras MK (2014) Clay settling in fresh and salt water. Environ Fluid Mech. doi:10.1007/s10652-014-9365-0

Te Slaa S, He Q, Sebastiaan van Maren D, Winterwerp JC (2013) Sedimentation processes in silt-rich sediment systems. Ocean Dyn 63:399-421

Toorman EA (1996) Sedimentation and self-weight consolidation: general unifying theory. Geotechnique 46(1):103-113

Toorman EA (1999) Sedimentation and self-weight consolidation: constitutive equations and numerical modelling. Geotechnique 49(6): 709-726

Toorman EA, Berlamont JE (1993) Settling and consolidation of mixtures of cohesive and non-cohesive sediments. In: Wang S (ed) Advances in hydro-science and engineering. University of Mississippi, p 606613

Torfs H, Mitchener H, Huysentruyt H, Toorman E (1996) Settling and consolidation of mud/sand mixtures. Coast Eng 29:27-45

Van Ledden M (2003) Sand-mud segregation in estuaries and tidal basins. Ph.D. thesis, Delft University of Technology, The Netherlands

Van LA, Pham Van Bang D (2013) Hindered settling of sand/mud flocs mixtures: from model formulation to numerical validation. Adv Water Res 53:1-11

Villaret C, Van LA, Huybrechts N, Pham Van Bang D, Boucher O (2010) Consolidation effects on morphodynamics modelling: application to the Gironde estuary. La Houille Blanche 6:15-24

Waeles B, Le Hir P, Lesueur, P (2008) A 3D morphodynamic processbased modelling of a mixed sand/mud coastal environment: the Seine estuary, France. In: Sediment and Ecohydraulics: INTERCOH 2005, Elsevier 
Wildenschild D, Roberts JJ, Carlberg ED (2000) Electrical properties of sand-clay mixtures: the effects of microstructure. Geophys Res Lett 27:3085-3089

Williamson HJ (1991) Tidal transport of mud/sand mixtures. Sediment distributions - a literature review. HR Wallingford Report SR 286

Winsauer WO, Shearin HM, Masson PH, Williams M (1952) Resistivity of brine-saturated sands in relation to pore geometry. AAPG Bull 36(2):253-277
Winterwerp JC (2002) On the flocculation and settling velocity of estuarine mud. Cont Shelf Res 22:1339-1360

Winterwerp JC, van Kesteren WGM (2004) Introduction to the physics of cohesive sediment in the marine environment. Developments in Sedimentology 56, Elsevier

Worthington PF (1993) The uses and abuses of the Archie equations, 1: the formation factor-porosity relationship. J Appl Geophys 30(3): $215-228$ 